\title{
Detection of Fungi and Oomycetes by Volatiles Using E-Nose and SPME-GC/MS Platforms
}

\author{
Jérémie Loulier ${ }^{1}$, François Lefort ${ }^{1, *}{ }^{\mathbb{D}}$, Marcin Stocki ${ }^{2}{ }^{(D}$, Monika Asztemborska ${ }^{3} \mathbb{D}$, \\ Rafał Szmigielski ${ }^{3}{ }^{(D}$, Krzysztof Siwek ${ }^{4}$, Tomasz Grzywacz ${ }^{4}$, Tom Hsiang ${ }^{5}$ (D) \\ Sławomir Ślusarski ${ }^{6}$, Tomasz Oszako ${ }^{2,6}{ }^{\mathbb{D}}$, Marcin Klisz ${ }^{7}{ }^{\mathbb{D}}$, Rafał Tarakowski ${ }^{8}{ }^{\mathbb{D}}$ and \\ Justyna Anna Nowakowska 9,*(D)
}

1 InTNE (Plants \& Pathogens Group), Hepia, University of Applied Sciences and Arts of Western Switzerland, 150 route de Presinge, 1254 Jussy, Switzerland; jeremie.loulier@bluewin.ch

2 Institute of Forest Sciences, Faculty of Civil Engineering and Environmental Sciences, Bialystok University of Technology, Wiejska 45E, 15-351 Bialystok, Poland; m.stocki@pb.edu.pl (M.S.); T.Oszako@ibles.waw.pl (T.O.)

3 Institute of Physical Chemistry, Polish Academy of Sciences, Kasprzaka 44/52, 01-224 Warsaw, Poland; monika@ichf.edu.pl (M.A.); ralf@ichf.edu.pl (R.S.)

4 Faculty of Electrical Engineering, Warsaw University of Technology, Koszykowa 75, 00-661 Warsaw, Poland; krzysztof.siwek@ee.pw.edu.pl (K.S.); tomasz.grzywacz@ee.pw.edu.pl (T.G.)

5 Environmental Sciences, University of Guelph, Guelph, ON N1G 2W1, Canada; thsiang@uoguelph.ca

6 Forest Protection Department, Forest Research Institute, Braci Leśnej 3, 05-090 Sękocin Stary, Poland; S.Slusarski@ibles.waw.pl

7 Department of Silviculture and Genetics, Forest Research Institute, Braci Leśnej 3, 05-090 Sękocin Stary, Poland; M.Klisz@ibles.waw.pl

8 Faculty of Physics, Warsaw University of Technology, Koszykowa 75, 00-662 Warsaw, Poland; Rafal.Tarakowski@pw.edu.pl

9 Institute of Biological Sciences, Cardinal Stefan Wyszynski University in Warsaw, Wóycickiego 1/3 Street, 01-938 Warsaw, Poland

* Correspondence: francois.lefort@hesge.ch (F.L.); j.nowakowska@uksw.edu.pl (J.A.N.); Tel.: +41-22-546-68-27 (F.L.); +48-22-569-6838 (J.A.N.)

Academic Editors: Simona Fabroni, Krystian Marszałek, Aldo Todaro and Wilfried Rozhon Received: 13 October 2020; Accepted: 4 December 2020; Published: 5 December 2020

\begin{abstract}
Fungi and oomycetes release volatiles into their environment which could be used for olfactory detection and identification of these organisms by electronic-nose (e-nose). The aim of this study was to survey volatile compound emission using an e-nose device and to identify released molecules through solid phase microextraction-gas chromatography/mass spectrometry (SPME-GC/MS) analysis to ultimately develop a detection system for fungi and fungi-like organisms. To this end, cultures of eight fungi (Armillaria gallica, Armillaria ostoyae, Fusarium avenaceum, Fusarium culmorum, Fusarium oxysporum, Fusarium poae, Rhizoctonia solani, Trichoderma asperellum) and four oomycetes (Phytophthora cactorum, P. cinnamomi, P. plurivora, P. ramorum) were tested with the e-nose system and investigated by means of SPME-GC/MS. Strains of F. poae, R. solani and T. asperellum appeared to be the most odoriferous. All investigated fungal species (except $R$. solani) produced sesquiterpenes in variable amounts, in contrast to the tested oomycetes strains. Other molecules such as aliphatic hydrocarbons, alcohols, aldehydes, esters and benzene derivatives were found in all samples. The results suggested that the major differences between respective VOC emission ranges of the tested species lie in sesquiterpene production, with fungi emitting some while oomycetes released none or smaller amounts of such molecules. Our e-nose system could discriminate between the odors emitted by P. ramorum, F. poae, T. asperellum and R. solani, which accounted for over $88 \%$ of the PCA variance. These preliminary results of fungal and oomycete detection make the e-nose device suitable for further sensor design as a potential tool for forest managers, other plant managers, as well as regulatory agencies such as quarantine services.
\end{abstract}


Keywords: fungi; oomycetes; VOCs; EI mass spectrometry; SPME-GC/MS; e-nose; sesquiterpenes

\section{Introduction}

Many phytopathogenic fungi and oomycetes species causing damping off and root rot diseases, are known to emit several secondary metabolites in the form of volatile organic compounds (VOCs), which can be genus- or species-specific. Other microbial secondary metabolites include, for instance, antibiotics, enzymes and toxins. Even though a great diversity of VOCs can be found from many different species, some volatiles are unique to particular species [1,2]. Volatile organic compounds are carbon molecules of molecular mass classically ranging from 100 to $500 \mathrm{Da}$ and chain size up to $\mathrm{C}_{20}$ that occur in gaseous form above $20^{\circ} \mathrm{C}$ and $10 \mathrm{~Pa}$ [3,4]. Generally lipophilic and thus poorly soluble in water, their boiling point is low and their vapor pressure at room temperature is high. Many of them have an associated characteristic odor [5].

Fungi produce VOC mixtures through primary and secondary metabolic pathways, and these diffuse through soil and into the atmosphere [6]. VOC production has been investigated in only ca. 100 of the over 100,000 described fungal species to date [7]. Fungal VOCs released through secondary metabolism seem to be at their highest during sporulation and mycotoxin production [8]. The secreted mixture profile varies according to many factors linked with the fungal strain itself and its growth environment, including physiological state, temperature, $\mathrm{pH}$, oxygen, nutrients, incubation time, etc. $[9,10]$.

Around one thousand different volatile compounds have to date been identified in a broad spectrum of microorganisms [11], produced mainly through glucose oxidation from diverse intermediates [6]. These molecules participate in various pathways of primary and secondary metabolism such as aerobic heterotrophic carbon metabolism, amino-acid catabolism, fatty acids degradation, fermentation, sulphur reduction and terpenoids biosynthesis [12]. Among these VOCs, more than one quarter are of unique fungal origin and include alcohols, aldehydes, alkenes, benzenoids, ketones, esters, terpenes and sulfuric compounds, although many other families are found as well, e.g., simple hydrocarbons, furans, heterocycles, phenols, thioalcohols, thioesters, etc. [6,13,14].

Sesquiterpenes are terpene hydrocarbons with an identical molecular formula of $\mathrm{C}_{15} \mathrm{H}_{24}$. Their skeletons are made of three isoprene units and can be acyclic or may include rings. Generally, sesquiterpenoids derive from sesquiterpenes through molecular rearrangements or oxidation. Sesquiterpene emission by fungi has been a field of particular interest over the past years [11,15], because this group of compounds may be key in discriminating between soil-borne fungi and Phytophthora spp. [16].

The exact reasons why microorganisms emit volatiles are not fully understood. It has been proposed that these molecules could be waste products resulting from microbial metabolism, and released for detoxification purposes [17]. Previous studies have shown that volatiles are involved in antimicrobial activity $[8,18]$. They have highlighted VOC involvement in interactions with distant microbial colonies in the form of infochemical compounds, influencing development, gene expression, and behavior of the recipient microorganisms [4]. During the last fifteen years, many trials were implemented in different research fields (for instance in environmental, food or medicinal sciences) to increase our understanding of microbial volatiles, facilitated by the development of efficient detection methods [19].

The first attempts of vapor characterization using sensing devices that can be considered as e-noses date back to 1960 [20], and they showed promise as tools for characterization of complex fungal VOC mixtures [21]. In general, an e-nose can refer to a wide range of devices including a set of gas sensors coupled with an information processing system and recognition software, founded on theoretical models as well as reference literature [22]. It was only in 1982 that intelligent e-noses able to classify odors really began to be developed [23], with the "electronic nose" appellation emerging for the first time [24]. A recent study managed to detect low concentrated matsutake alcohol by means of 
an e-nose using surface acoustic wave technology, which makes it a promising candidate for future developments in fungal e-nose detection [25].

In phytopathology, pathogen identification is usually achieved through study of symptoms, pathogen isolation, morphological description and possibly immunological testing or DNA sequence analyses. However, infection symptoms are sometimes invisible, hidden underground or non-specific for the pathogenic agent, which complicates proper diagnosis. Pathogen isolation, immunological tests, and DNA tests require laboratory work making the operation expensive, laborious and time-consuming, thus not well suited for large-scale monitoring [26]. In this regard, e-nose could serve as a preliminary screening tool allowing a quick diagnosis that could be achieved even without any symptoms being visible on the plant, as well as an efficient field monitoring applicable at the scale of single seeds, entire plants, or food storage installations.

To improve the performance of this technology for application to forest sciences or related fields, identification of pathogen-specific VOC profiles could be a key point for improved e-nose sensing efficiency. The aim of this work was to test an electronic nose developed by the Warsaw University of Technology, originally designed to identify bacterial and fungal rot in food, to the field of phytopathology. We focused on detection of eight well-known fungal pathogens i.e., Armillaria spp., Fusarium spp., and Rhizoctonia solani causing root rot damage e.g., in Scots pine, black alder and European oak seedlings [27]. The other tested fungus (Trichoderma asperellum) is not pathogenic and rather considered as a biocontrol agent in many forest and ornamental nurseries [27]. Furthermore, four Phytophthora species were investigated, since these are recognized as soil-borne pathogens of many forest tree species, including European oak, European beech, silver birch and black alder [28]. Two working hypotheses were tested. First, we assumed that the e-nose apparatus can be a suitable detection system for fungi and fungi-like organisms. The second hypothesis was that some VOCs are species-specific and because these VOCs emitted by microorganisms can be detected, this can be used to differentiate the investigated microbial species. To test these hypotheses we did the following: (i) selected and developed pure cultures of the studied microorganisms; (ii) investigated the gas composition in the air with e-nose technology; (iii) performed a precise detection of VOCs using two independent SPME-GC/MS analytical methods, and finally (iv) speculated on the extent the emitted compounds are useful for identification of a given microorganism.

\section{Results}

\subsection{E-Nose Gas Detection}

Distribution of the overall averaged values of gas detected by twelve differential sensor signals differed among all fourteen treatments (Figure 1). The two control treatments yielded somewhat divergent results because mean signal intensities obtained over four weeks of study showed clean empty glass flasks to be inducing a very weak response from e-nose sensors, whereas the potato dextrose agar (PDA) medium generated a stronger reaction from the sensing device on average (Figure 1a,b).

The e-nose detection showed that $A$. gallica and A. ostoyae cultures emitted low levels of volatiles similar to the empty flask control (Figure 1c,d). All Fusarium species provoked a clear reaction from e-nose sensors, with a slightly higher signal strength variation among replicates (Figure 1e-h), but still at the level comparable to the signal intensity for PDA medium (Figure 1e-g). The overall odor was thus moderate, except for $F$. poae which appeared to be one of the most odoriferous tested strains (Figure 1h), with an immediate and powerful rise in sensor signal. 


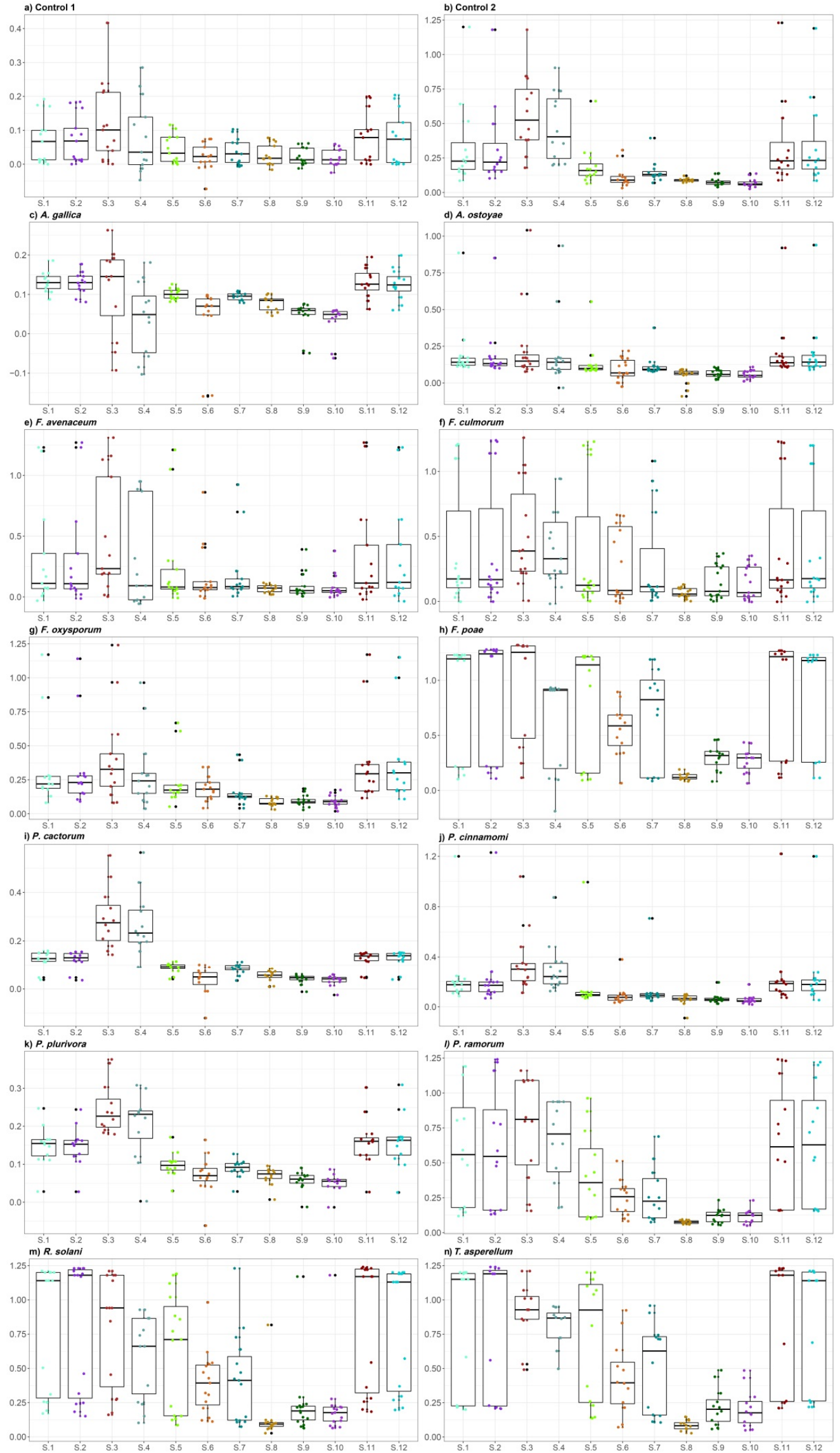


Figure 1. Distribution of the overall averaged values of twelve differential sensor original signals for the respective 14 treatments; e.g., (a) control 1 (empty flask); (b) control 2 (PDA medium); (c) A. gallica; (d) A. ostoyae; (e) F. avenaceum; (f) F. culmorum; (g) F. oxysporum; (h) F. poae; (i) P. cactorum; (j) P. cinnamomi; (k) P. plurivora; (1) P. ramorum; (m) R. solani; (n) T. asperellum.

Phytophthora species generated an overall feeble reaction from the e-nose (Figure 1i-1), except for P. ramorum which produced a strong odor (Figure 11), only slightly weaker than F. poae, R. solani and T. asperellum. Signal strength usually increased quickly after the e-nose air inlet was introduced into the P. ramorum atmosphere. Like F. poae, $R$. solani and T. asperellum emitted a very strong odor highlighted during e-nose testing, with the introduction of the air inlet into a sample atmosphere which made the sensor signals instantly and strongly increase (Figure $1 \mathrm{~m}, \mathrm{n}$ ). To sum up, the strains of F. avenaceum, F. culmorum and F. oxysporum along with $P$. ramorum generated less intense average reactions from the sensing device (Figure 1e-g,l), but these were however still stronger than for Armillaria and remaining Phytophthora strains whose odors appeared to be very weak (Figure 1c,d,i-k).

No clear pattern over time could be found among the tested species, probably because of the low level of repeated sampling (usually 3) per week of study which did not allow adequate assessment of temporal variation in emissions. The PDA medium was more constant between repeated observations, although the signal strength increased over time, possibly as the medium dried out. Sensors 1, 2, 3, 4, 11 and 12 overall systematically gave a stronger response to volatiles, while sensors 5, 6, 7 and even more 8, 9, 10 yielded weaker signals (Figure 1).

Based on correlation analyses between eigenvalues, we found that the variance between signals mostly depended on the first principal component (PC1) and only slightly on the second principal component (PC2) (93.87\% and 03.26\%, respectively; Figure 2, Table S2). This enabled us to deduce using the PCA plot that the odors generated by P. ramorum, F. poae, T. asperellum and R. solani were readily distinguishable due to the location of the microorganisms on the biplot and grouping pattern confirmed by hierarchical clustering analysis (Figure S1, Table S2).

\subsection{Determination of VOC Emitted by Fungi and Oomycetes}

In our study, two SPME fibers were compared (PDMS vs. PDMS/Carboxen). The results revealed that the PDMS fiber system was less applicable for volatiles released by fungi and oomycetes, because during GC/MS analyses a number of silicone-derived contaminants were observed. The latter could be explained by the chemical destruction of a DMS surface coating by biogenic volatiles released. Hence, only results obtained from the sampling of volatiles with a DMS/Carboxen fiber are presented.

The molecular identification was carried out using threefold approach: matching with GC/EI MS libraries, both commercial (NIST + Willey) and in-house built, comparison of Kovats indices (RI) (measured + reported elsewhere) and authentic standards. The last approach was applied only when standards were available, and thus was confined to common organics, such as hexanal, heptanal or benzaldehyde. However, a few unknowns from fungal emissions, e.g., 1,3,4,5,6,7-hexahydro-2,5,5-trimethyl-2H-2,4a-ethanonaphthalene, were tentatively elucidated using the two first approaches, because of the lack of authentic standards. The identification with standards (authentic not internal) is the gold standard for the thorough identification.

To identify components, both mass spectral data and the calculated retention indices were used. Mass spectrometric identification not confirmed by the retention index was considered as tentative. The background emissions from controls, empty containers and PDA medium were subtracted. Some of the volatiles found through GC/MS, such as aliphatic hydrocarbons, alcohols, aldehydes, esters and aromatic derivatives were present in samples from all treatments (including controls), but all the investigated fungi species (except $R$. solani) produced sesquiterpenes of variable quantities. However, the tested oomycete strains generally produced fewer detectable substances, even less than non-inoculated controls, including those compounds mentioned above (Table 1). 


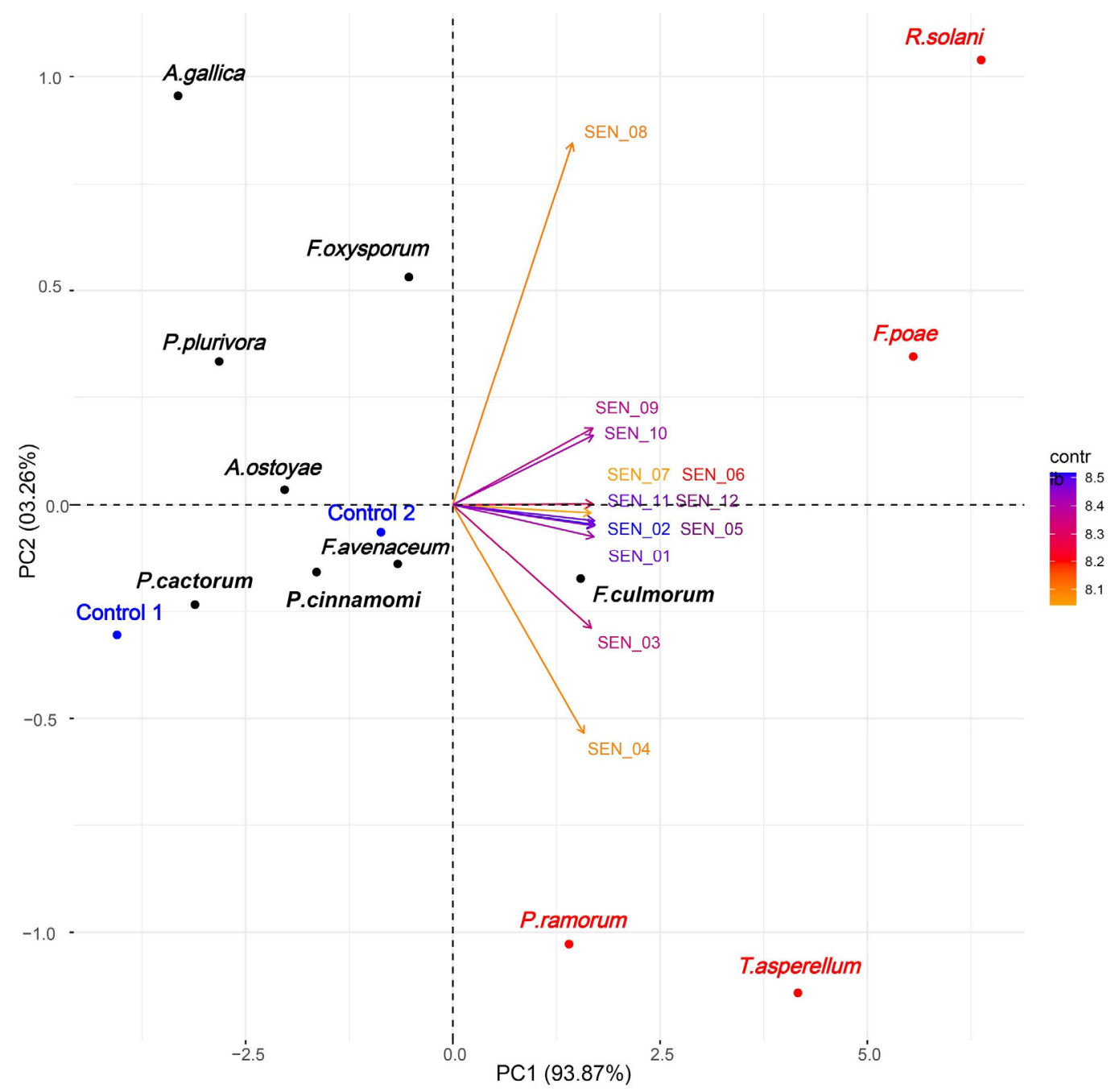

Figure 2. Variability of twelve differential sensor signals assigned to the twelve investigated microorganisms. Vectors were colored according to their contribution to total variance: orange-low, blue-high. Blue dots represent controls: 1-empty flask, and 2-PDA medium; red dots-microorganisms with the most pronounced eigenvalues, black dots-microorganisms with less pronounced eigenvalues (cf. Table S2, Figure S1).

Table 1. The VOC emission pattern detected using a SPME-GC/MS method in the headspace atmosphere of samples tested at BUT. Similarity indices (SI) were obtained by comparing a profile of the EI mass spectrum of a given VOC compound with the reference one in NIST Mass Spectral Database library; these values represent the confidence in the molecular identification.

\begin{tabular}{|c|c|c|c|c|c|c|}
\hline$t_{R}{ }^{1}[\min ]$ & $\mathrm{SI}^{2} \%$ & $\mathbf{R I}_{\mathrm{Exp}}{ }^{3}$ & $\mathrm{RI}_{\mathrm{Lit}} 4$ & Ref. & $\begin{array}{l}\text { Peak Area per } \\
\text { Treatment }\end{array}$ & Name of Compound ${ }^{5}$ \\
\hline & & \multicolumn{5}{|c|}{ (1) Empty Container } \\
\hline 7.19 & 65 & 902 & 901 & [29] & $17,674,234$ & Heptanal $^{++a}$ \\
\hline 10.05 & 80 & 1003 & 998 & [29] & $40,444,566$ & Octanal $^{++a}$ \\
\hline 10.82 & 28 & 1029 & 1027 & [30] & $21,189,032$ & 2-Ethyl-hexanol a \\
\hline 13.05 & 79 & 1104 & 1100 & [29] & $76,538,207$ & Nonanal ${ }^{++a}$ \\
\hline 15.98 & 53 & 1206 & 1201 & [29] & $14,513,924$ & Decanal $++a$ \\
\hline 18.06 & - & 1281 & - & - & $14,724,741$ & Unknown compound \\
\hline 18.77 & - & 1307 & - & - & $13,630,063$ & Unknown compound \\
\hline 21.21 & 32 & 1400 & 1400 & [29] & $6,427,563$ & Tetradecane ${ }^{++a}$ \\
\hline 21.44 & 58 & 1409 & 1408 & [29] & $17,444,416$ & Dodecanal $^{++a}$ \\
\hline
\end{tabular}


Table 1. Cont.

\begin{tabular}{|c|c|c|c|c|c|c|}
\hline$t_{R}{ }^{1}[\min ]$ & $\mathrm{SI}^{2} \%$ & $\mathrm{RI}_{\mathrm{Exp}}{ }^{3}$ & $\mathrm{RI}_{\text {Lit }}{ }^{4}$ & Ref. & $\begin{array}{c}\text { Peak Area per } \\
\text { Treatment }\end{array}$ & Name of Compound ${ }^{5}$ \\
\hline 24.07 & 78 & 1516 & 1514 & [31] & $47,388,559$ & Butylated Hydroxytoluene ${ }^{++a}$ \\
\hline \multicolumn{7}{|c|}{ (2) PDA Medium } \\
\hline 4.77 & 50 & 804 & 801 & [29] & $19,939,473$ & Hexanal $^{+a}$ \\
\hline 5.48 & 57 & 834 & 828 & [29] & $11,223,384$ & Furfural ${ }^{+a}$ \\
\hline 7.18 & 31 & 902 & 901 & [29] & $39,366,443$ & Heptanal $^{++a}$ \\
\hline 8.80 & 72 & 959 & 952 & [29] & $60,063,839$ & Benzaldehyde $^{a}$ \\
\hline 9.74 & 87 & 992 & 984 & [29] & $31,027,584$ & 2-Pentyl-furan ${ }^{\mathrm{b}}$ \\
\hline 10.05 & 74 & 1003 & 998 & [29] & $11,751,703$ & Octanal $^{++a}$ \\
\hline 10.81 & 44 & 1029 & 1027 & [30] & $32,462,061$ & 2-Ethyl-hexanol ${ }^{\text {a }}$ \\
\hline 11.23 & 73 & 1043 & 1036 & [29] & $73,539,705$ & Benzeneacetaldehyde $^{++a}$ \\
\hline 12.96 & 21 & 1101 & 1100 & [29] & $12,884,326$ & Undecane ${ }^{+a}$ \\
\hline 13.04 & 80 & 1104 & 1100 & [29] & $41,840,277$ & Nonanal $^{++a}$ \\
\hline 15.48 & - & 1189 & - & - & $4,687,953$ & Unknown compound \\
\hline 15.83 & 30 & 1201 & 1200 & [29] & $4,893,511$ & Dodecane ${ }^{+a}$ \\
\hline 15.97 & 50 & 1206 & 1201 & [29] & $10,723,873$ & Decanal $^{++a}$ \\
\hline 18.13 & - & 1284 & - & - & $5,876,115$ & Unknown compound \\
\hline 18.77 & - & 1307 & - & - & $4,815,975$ & Unknown compound \\
\hline 21.43 & 44 & 1409 & 1408 & [29] & $11,027,672$ & Dodecanal ${ }^{++a}$ \\
\hline 24.06 & 74 & 1515 & 1514 & [31] & $14,730,122$ & Butylated Hydroxytoluene ${ }^{++a}$ \\
\hline \multicolumn{7}{|c|}{ (3) A. gallica } \\
\hline 8.80 & 47 & 959 & $n / a^{6}$ & - & $300,374,347$ & \multirow{4}{*}{$\begin{array}{c}\text { (2E)-4,4-Dimethyl-2-pentenal } \\
\text { (E)-2-Octen-1-al b } \\
\text { 1,3,4,5,6,7-Hexahydro-2,5 } \\
5 \text {-trimethyl-2H-2, } \\
\text { 4a-ethanonaphthalene } \\
\text { (Z)- } \alpha \text {-Bisabolene } \\
\text { ca }\end{array}$} \\
\hline 11.73 & 53 & 1060 & 1049 & [29] & $62,813,700$ & \\
\hline 20.87 & 10 & 1387 & $\mathrm{n} / \mathrm{a}$ & - & $611,543,126$ & \\
\hline \multirow[t]{2}{*}{23.89} & 26 & 1506 & 1506 & [29] & $74,690,325$ & \\
\hline & & & \multicolumn{4}{|c|}{ (4) A. ostoyae } \\
\hline 8.80 & 49 & 959 & $\mathrm{n} / \mathrm{a}$ & - & $87,776,838$ & (2E)-4,4-Dimethyl-2-pentenal c \\
\hline 11.74 & 35 & 1060 & 1049 & [29] & $20,166,139$ & (E)-2-Octen-1-al ${ }^{\mathrm{b}}$ \\
\hline 18.49 & 21 & 1297 & 1293 & [29] & $8,070,650$ & 2-Undecanone ${ }^{a}$ \\
\hline 20.83 & 43 & 1386 & $\mathrm{n} / \mathrm{a}$ & - & $106,170,662$ & $\begin{array}{c}\text { 1,3,4,5,6,7-Hexahydro-2, } \\
5,5 \text {-trimethyl-2H-2, } \\
\text { 4a-ethanonaphthalene }\end{array}$ \\
\hline 22.49 & 59 & 1451 & 1440 & [29] & $43,908,793$ & $\beta$-Barbatene ${ }^{a}$ \\
\hline \multirow[t]{2}{*}{24.42} & 34 & 1531 & 1522 & [29] & $24,134,794$ & $\delta$-Cadinene ${ }^{+a}$ \\
\hline & & & \multicolumn{4}{|c|}{ (5) F. avenaceum } \\
\hline 3.28 & 76 & 712 & 735 & [32] & $2,653,753$ & 2,4-Dimethylfuran ${ }^{+b}$ \\
\hline 9.13 & 23 & 971 & 970 & [33] & $3,974,721$ & Mesitilene $^{+a}$ \\
\hline 10.91 & 76 & 1032 & 1029 & [29] & $9,540,610$ & $\beta$-Phellandrene ${ }^{a}$ \\
\hline 21.59 & 35 & 1415 & 1407 & [29] & $11,961,247$ & Longifolene ${ }^{\mathrm{a}}$ \\
\hline \multirow[t]{2}{*}{24.46} & 73 & 1532 & 1519 & [29] & $3,401,805$ & $\beta$-Bazzanene ${ }^{+a}$ \\
\hline & & \multicolumn{5}{|c|}{ (6) F. culmorum } \\
\hline 1.62 & 77 & $<500$ & 448 & [34] & $163,586,144$ & Ethanol $^{\mathrm{a}}$ \\
\hline 2.25 & 96 & 573 & 606 & [29] & $45,234,113$ & Ethyl acetate $+\mathrm{a}$ \\
\hline 3.55 & 41 & 728 & 731 & [29] & $6,085,804$ & Isoamyl alcohol + a \\
\hline 3.61 & 56 & 732 & 724 & [29] & $3,371,660$ & 2-Methyl-butanol a \\
\hline 10.91 & 18 & 1032 & 1029 & [29] & $177,256,946$ & $\beta$-Phellandrene ${ }^{a}$ \\
\hline 21.80 & 43 & 1424 & 1408 & [29] & $20,993,355$ & Acora-3,7(14)-diene ${ }^{+b}$ \\
\hline \multirow[t]{2}{*}{22.23} & $\operatorname{man}^{7}$ & 1441 & 1432 & [29] & $138,760,275$ & $\beta$-Copaene ${ }^{+a}$ \\
\hline & & & \multicolumn{4}{|c|}{ (7) F. oxysporum } \\
\hline 6.02 & 78 & 854 & 864 & [35] & 845,609 & 2-Furanmethanol +b \\
\hline 7.96 & 59 & 930 & 927 & [36] & $2,621,568$ & Hexyl formate $+\mathrm{a}$ \\
\hline 8.86 & 79 & 961 & 952 & [29] & $49,523,292$ & Benzaldehyde ${ }^{+a}$ \\
\hline 9.65 & 68 & 989 & 979 & [29] & $5,057,096$ & 3-Octanone ${ }^{\mathrm{a}}$ \\
\hline 10.27 & 71 & 1010 & 960 & [29] & $2,393,859$ & Isoamyl propionate $+\mathrm{a}$ \\
\hline 10.90 & 54 & 1032 & $\mathrm{n} / \mathrm{a}$ & - & $63,835,818$ & Heptyl formate $^{+a}$ \\
\hline 21.98 & 33 & 1431 & 1419 & [29] & $4,969,490$ & $\beta$-Cedrene ${ }^{a}$ \\
\hline 22.49 & 90 & 1451 & $\mathrm{n} / \mathrm{a}$ & - & $23,065,220$ & $\begin{array}{l}\text { 3-Chloro-4-methoxy } \\
\text {-benzaldehyde }\end{array}$ \\
\hline 22.77 & 20 & 1463 & $\mathrm{n} / \mathrm{a}$ & - & $8,382,097$ & $\begin{array}{l}\text { 2,4-Dichloro-3-methoxy-1 } \\
\text {-benzene carbonyl chloride }+ \text { c }\end{array}$ \\
\hline
\end{tabular}


Table 1. Cont.

\begin{tabular}{|c|c|c|c|c|c|c|}
\hline$t_{R}{ }^{1}[\min ]$ & $\mathrm{SI}^{2} \%$ & $\mathbf{R I}_{\operatorname{Exp}}{ }^{3}$ & $\mathrm{RI}_{\mathrm{Lit}} 4$ & Ref. & $\begin{array}{l}\text { Peak Area per } \\
\text { Treatment }\end{array}$ & Name of Compound ${ }^{5}$ \\
\hline \multirow[t]{2}{*}{23.34} & 93 & 1486 & 864 & [35] & $2,740,362$ & $\begin{array}{l}\text { 3,4-Dimethoxy-benzaldehyde } \\
\qquad+\mathrm{a}\end{array}$ \\
\hline & & & \multicolumn{4}{|c|}{ (8) F. poae } \\
\hline 9.43 & 81 & 981 & 974 & [29] & $93,704,125$ & 1-Octen-3-ol ${ }^{\mathrm{a}}$ \\
\hline 9.79 & 36 & 994 & 988 & [29] & $166,758,547$ & Myrcene $^{+a}$ \\
\hline 13.39 & 59 & 1116 & 1122 & [37] & $100,643,564$ & 1-Ethyl-4-methoxy-benzene ${ }^{b}$ \\
\hline 16.68 & 41 & 1231 & 1223 & [29] & $36,663,640$ & Citronellol $+\mathrm{a}$ \\
\hline 20.10 & 28 & 1358 & 1350 & [29] & $106,101,600$ & $\alpha$-Longipinene ${ }^{+a}$ \\
\hline 20.65 & 16 & 1379 & 1371 & [29] & $108,987,407$ & Longicyclene ${ }^{+a}$ \\
\hline 21.43 & man. & 1409 & 1400 & [29] & $248,606,376$ & $\beta$-Longipinene ${ }^{+b}$ \\
\hline 21.65 & 37 & 1418 & 1407 & [29] & $1,390,824,920$ & Longifolene ${ }^{a}$ \\
\hline 21.81 & - & 1427 & - & - & $482,683,621$ & Unknown sesquiterpene \\
\hline 21.91 & 22 & 1428 & 1419 & [29] & $195,664,192$ & $\beta$-Ylangene $+a^{1}$ \\
\hline 22.31 & - & 1444 & - & - & $954,381,082$ & Unknown sesquiterpene \\
\hline 22.55 & 55 & 1454 & 1440 & [29] & $129,567,010$ & $\beta$-Barbatene ${ }^{+a}$ \\
\hline 22.68 & 16 & 1459 & 1449 & [29] & $117,848,857$ & $\alpha$-Himachalene $+\mathrm{a}$ \\
\hline 22.75 & 50 & 1462 & 1454 & [29] & $143,907,373$ & $(E)-\beta$-Farnesene ${ }^{+a}$ \\
\hline 23.02 & 20 & 1473 & 1466 & [29] & $116,555,130$ & $\alpha$-Acoradiene ${ }^{+a}$ \\
\hline 23.38 & 16 & 1487 & 1481 & [29] & $134,783,119$ & $\gamma$-Himachalene ${ }^{+a}$ \\
\hline 23.98 & 43 & 1512 & $\mathrm{n} / \mathrm{a}$ & - & $44,779,678$ & $\begin{array}{l}\text { 8-Isopropenyl-1,5-dimethyl-1, } \\
\text { 5-cyclodecadiene }{ }^{+c}\end{array}$ \\
\hline 24.05 & 17 & 1515 & 1505 & [29] & $51,262,732$ & $\beta$-Bisabolene ${ }^{+a}$ \\
\hline 25.03 & - & 1557 & - & - & $42,987,721$ & Unknown sesquiterpene \\
\hline \multirow[t]{2}{*}{26.31} & 60 & 1612 & 1599 & [29] & $1,576,920,976$ & Longiborneol $^{+\mathrm{a}}$ \\
\hline & & \multicolumn{5}{|c|}{ (9) P. cactorum } \\
\hline 1.71 & 86 & $<500$ & 500 & [34] & $5,827,788$ & Acetone $^{a}$ \\
\hline 3.75 & 97 & 740 & 744 & [38] & $4,459,515$ & Dimethyl disulfide $^{\mathrm{b}}$ \\
\hline 4.12 & - & 763 & - & - & $4,321,348$ & Unknown compound \\
\hline 6.35 & 60 & 868 & 863 & [29] & $25,809,441$ & 1-Hexanol ${ }^{+a}$ \\
\hline 9.15 & 58 & 971 & 959 & [29] & $5,111,166$ & 1-Heptanol +a \\
\hline 9.42 & 75 & 981 & 974 & [29] & $19,848,783$ & 1-Octen-3-ol a \\
\hline 9.65 & 76 & 989 & 979 & [29] & $12,627,315$ & 3-Octanone ${ }^{\mathrm{a}}$ \\
\hline 9.81 & 88 & 995 & 984 & [29] & $4,284,441$ & 2-Pentyl-furan ${ }^{\mathrm{a}}$ \\
\hline 12.05 & 22 & 1071 & 1060 & [29] & $2,508,277$ & 2-Octen-1-ol +a \\
\hline \multirow[t]{2}{*}{12.13} & 19 & 1073 & 1063 & [29] & $4,044,266$ & 1-Octanol $+\mathrm{a}$ \\
\hline & & \multicolumn{5}{|c|}{ (10) P. cinnamomi } \\
\hline 1.61 & 97 & $<500$ & 448 & [31] & $9,483,339$ & Ethanol $^{\mathrm{a}}$ \\
\hline 9.43 & 56 & 981 & 974 & [29] & $2,215,655$ & 1-Octen-3-ol ${ }^{\mathrm{a}}$ \\
\hline 10.88 & 47 & 1031 & 1027 & [30] & $5,251,305$ & 2-Ethyl-hexanol ${ }^{\mathrm{a}}$ \\
\hline \multirow[t]{2}{*}{18.13} & 85 & 1284 & 1282 & [39] & $1,001,882$ & 4-Ethyl-2-methoxy-phenol ${ }^{+b}$ \\
\hline & & \multicolumn{5}{|c|}{ (11) P. plurivora } \\
\hline 1.71 & 84 & $<500$ & 500 & {$[34]$} & $4,481,938$ & Acetone $^{\mathrm{a}}$ \\
\hline 3.20 & 64 & 707 & 711 & [40] & $2,268,583$ & Acetoin $^{+a}$ \\
\hline 6.37 & 36 & 869 & 863 & [29] & $1,803,069$ & Hexanol $^{+a}$ \\
\hline 7.51 & 76 & 914 & 933 & [41] & $3,627,373$ & 4-Hydroxy-butanoic acid $+b$ \\
\hline 8.14 & 16 & 936 & 932 & [29] & $1,684,400$ & $\alpha$-Pinene ${ }^{+a}$ \\
\hline \multirow[t]{2}{*}{10.35} & 14 & 1013 & 1008 & [29] & $1,103,050$ & $\Delta$-3-Carene ${ }^{+a}$ \\
\hline & & \multicolumn{5}{|c|}{ (12) P. ramorum } \\
\hline 1.16 & 98 & $<500$ & 448 & {$[34]$} & $20,885,799$ & Ethanol $^{\mathrm{a}}$ \\
\hline 3.55 & 74 & 728 & 730 & [42] & $80,424,948$ & 3-Methyl-butanol a \\
\hline 3.61 & 74 & 732 & 724 & [29] & $26,123,097$ & 2-Methyl-butanol a \\
\hline 9.43 & 72 & 981 & 974 & [29] & $8,370,575$ & 1-Octen-3-ol ${ }^{\mathrm{a}}$ \\
\hline 9.65 & 70 & 989 & 979 & [29] & $11,144,929$ & 3-Octanone ${ }^{\mathrm{a}}$ \\
\hline \multirow[t]{2}{*}{13.37} & 87 & 1116 & 1106 & [29] & $48,377,677$ & 2-Phenylethanol +a \\
\hline & & & \multicolumn{4}{|c|}{ (13) R. solani } \\
\hline 1.71 & 87 & $<500$ & 500 & [34] & $3,565,392$ & Acetone $^{\mathrm{a}}$ \\
\hline 9.42 & 74 & 981 & 974 & [29] & $24,589,405$ & 1-Octen-3-ol ${ }^{\mathrm{a}}$ \\
\hline 9.65 & 62 & 989 & 979 & [29] & $3,438,485$ & 3-Octanone ${ }^{a}$ \\
\hline 9.90 & 75 & 998 & 988 & [29] & $6,372,403$ & 3-Octanol +a \\
\hline 15.56 & - & 1191 & - & - & $4,474,717$ & Unknown compound \\
\hline
\end{tabular}


Table 1. Cont.

\begin{tabular}{|c|c|c|c|c|c|c|}
\hline$t_{R}{ }^{1}[\min ]$ & $\mathrm{SI}^{2} \%$ & $\mathrm{RI}_{\mathrm{Exp}}{ }^{3}$ & $\mathrm{RI}_{\mathrm{Lit}} 4$ & Ref. & $\begin{array}{l}\text { Peak Area per } \\
\text { Treatment }\end{array}$ & Name of Compound ${ }^{5}$ \\
\hline & & \multicolumn{5}{|c|}{ (14) T. asperellum } \\
\hline 1.71 & 82 & $<500$ & 500 & [34] & $3,920,210$ & Acetone $^{\mathrm{a}}$ \\
\hline 3.56 & 62 & 729 & 730 & [41] & $7,870,509$ & 3-Methyl-butanol ${ }^{\mathrm{a}}$ \\
\hline 3.62 & 45 & 733 & 724 & [29] & $4,424,960$ & 2-Methyl-butanol ${ }^{\mathrm{a}}$ \\
\hline 3.76 & 98 & 741 & 744 & [38] & $11,829,339$ & Dimethyl disulfide $\mathrm{e}^{\mathrm{b}}$ \\
\hline 7.26 & - & 905 & - & - & $153,721,663$ & Unknown compound \\
\hline 13.01 & - & 1103 & - & - & $20,319,451$ & Unknown compound \\
\hline 13.38 & 85 & 1116 & 1106 & [29] & $37,177,146$ & 2-Phenyethanol ${ }^{+a}$ \\
\hline 20.08 & - & 1357 & - & - & $70,272,034$ & Unknown sesquiterpene \\
\hline 20.91 & 44 & 1389 & 1380 & [29] & $229,806,310$ & Daucene $^{+b}$ \\
\hline 21.81 & man. & 1424 & 1412 & {$[29]$} & $25,748,186$ & 2 -epi- $\beta$-Funebrene ${ }^{+b}$ \\
\hline 21.98 & 50 & 1431 & 1419 & [29] & $86,596,372$ & $\beta$-Cedrene ${ }^{\mathrm{a}}$ \\
\hline 23.93 & 28 & 1510 & 1500 & [29] & $118,470,969$ & Isodaucene ${ }^{+b}$ \\
\hline 24.27 & 21 & 1524 & 1513 & [29] & $52,189,482$ & $\gamma$-Cadinene $+\mathrm{a}$ \\
\hline 24.63 & 40 & 1540 & 1530 & [29] & $194,592,295$ & Dauca-4(11)-8-diene ${ }^{+a}$ \\
\hline 25.49 & - & 1576 & - & - & $8,894,971$ & Unknown sesquiterpene \\
\hline 27.81 & - & 1679 & - & - & $15,501,124$ & Unknown sesquiterpene \\
\hline 28.31 & 27 & 1701 & $\mathrm{n} / \mathrm{a}$ & - & $15,437,838$ & $\begin{array}{l}\text { 1-Isopropyl-4,8-dimethylspiro } \\
\text { [4.5]dec-8-en-7-one }\end{array}$ \\
\hline 30.26 & - & 1793 & - & - & $21,104,266$ & Unknown sesquiterpene \\
\hline
\end{tabular}

${ }^{1}$ retention time; ${ }^{2}$ similarity index; ${ }^{3}$ Kovats retention index calculated from experimental data; ${ }^{4}$ Kovats retention index from literature; ${ }^{5}$ compound exclusively present there $(+)$ or present only in controls $(++) ;{ }^{6}$ data not available: ${ }^{7}$ manual matching; ${ }^{a}$ compound identified using retention time of authentic standard, matching with MS library and comparison with reported $\mathrm{KI} ;{ }^{\mathrm{b}}$ compound identified by matching with MS library and comparison with reported $\mathrm{KI} ;{ }^{c}$ compound identified by matching with MS library.

\subsubsection{Control Treatments}

The empty container control atmosphere appeared to be surprisingly rich in ten volatiles (Table 1 , treatment 1), whose origin was probably linked to the silicone ring adjoined to the underside of the lid by the manufacturer to allow hermetic closure of the flask. This was consistent with the e-nose sensing a very weak, but still detectable, signal for this control treatment (Figure 1a). Even though the e-nose sensors showed more signals from PDA medium control samples than the empty container control ones (Figure 1b), respective molecule abundances of both chromatograms belonged to the same order of magnitude $\left(10^{7}\right)$.

\subsubsection{Armillaria Species}

The SPME-GC/MS data indicated a similar emission pattern in two Armillaria treatments which is in accord with the results obtained from e-nose analysis (Figure 1c,d). Two Armillaria species shared three similar VOCs i.e., (2E)-4,4-dimethyl-2-pentenal, (E)-2-octen-1-al, and 1,3,4,5,6,7-hexahydro-2,5,5-trimethyl-2H-2,4a-ethanonaphthalene (Table 1, treatments 3 and 4 ). Some sesquiterpenes, i.e., $\delta$-cadinene, $(Z)$ - $\alpha$-bisabolene, and 1,3,4,5,6,7-hexahydro-2,5,5,-trimethyl-2H-2,4a-ethanonaphthalene were present only in Armillaria atmosphere suggesting an inherent emission by the fungi (Table 1, treatments 3 and 4). Another sesquiterpene, $\beta$-barbatene, was detected in both A. ostoyae (a basidiomycete) and $F$. poae (an ascomycete) implying common VOC emission (Table 1, treatment 4 and 8 ) between two different fungal divisions.

\subsubsection{Fusarium Species}

The three Fusarium species showed an interesting pattern of VOC emission. Longifolene was detected among the most common volatiles in only $F$. avenaceum and $F$. poae (Table 1 , treatments 5 and 8). Subsequently, production of $\beta$-phellandrene by F. avenaceum and F. culmorum was observed. $\alpha$-pinene and $\Delta$-3-Carene were detected in P. plurivora (Table 1, treatment 11). These compounds were not found in the non-inoculated media controls. Finally, F. culmorum contained ethanol, in common with P. cinnamomi and P. ramorum (Table 1, treatments 6, 10 and 12). Consistent with e-nose analysis 
results, the F. poae GC/MS data showed a higher molecular abundance magnitude $\left(10^{8}\right)$ (and remarkable compound diversity) than other Fusarium species (usually at $10^{7}$ ). The compound 1-octen-3-ol was found in F. poae, P. cactorum, P. cinnamomi and R. solani (Table 1, treatments 8, 9 and 13), supporting the idea of common molecules emitted across varied taxa.

\subsubsection{Phytophthora Species}

Acetone was shared between two oomycetes P. cactorum and P. plurivora while ethanol was shared between P. cinnamomi and P. ramorum (Table 1, treatments 9 and 11). Other volatiles were present in different species of oomycetes and fungi, e.g., 3-octanone detected in P. cactorum, P. ramorum and R. solani (Table 1, treatment 9 and 13), and 1-octen-3-ol found in the P. cactorum, P. ramorum, F. poae and R. solani (Table 1, treatments 8, 9 and 13). The $\alpha$-pinene and $\Delta$-3-Carene emitted by P. plurivora were the only terpene compounds found in a Phytophthora species during this research (Table 1, treatment 11). Abundance of P. ramorum compounds was higher than for other Phytophthora sp., in accordance with e-nose analysis results. Among the studied Oomycetes, only P. ramorum showed the highest level and similar order of overall VOC emission as Armillaria treatments (Table 1, treatments 3, 4 and 13). SPME-GC/MS analysis revealed presence of 2-phenylethanol in both P. ramorum and T. asperellum (Table 1, treatments 12 and 14).

\subsubsection{Rhizoctonia and Trichoderma Species}

The $R$. solani chromatogram differed from the signal indicated by e-nose sensors (Figure $1 \mathrm{~m}$ ). Higher amounts of 1-octen-3-ol were found in R. solani than in F. poae and P. cactorum (Table 1, treatments 8, 9 and 13). Consistent with e-nose results (Figure 1n), SPME-GC/MS analysis yielded for T. asperellum high richness of VOCs emitted with relatively high abundance magnitude (almost $10^{8}$ ).

\section{Discussion}

The sustainability (durability) and biodiversity of forest stands in Poland depends not only sustainable forest management but also on integrated pest management. Foresters cannot afford to allow pests to escape from nurseries to forest plantations together with the sold seedlings. Visual inspection often fails (asymptomatic plants), so forest managers are looking for new tools to support their work. In particular, pesticides applied in nurseries mask diseases, which in suitable conditions after outplanting will start to develop e.g., Phytophthora in wet forest sites. New devices should allow a quick detection of potential pathogens, particularly for emerging diseases. Among them are the foreign, invasive oomycetes (Phytophthora, Pythium) and other soil borne pathogens in the genera Fusarium, Rhizoctonia or Cylindrocarpon. All those organisms growing in pure cultures have distinctive strong odors because of volatile secondary metabolite production, but no instrument has been used in practice for routine detection of pathogen by forest managers. In the present research, we focused on assessing the possibility of designing an electronic nose to recognize genera or species of some pathogenic organisms often found in forest nurseries. This e-nose apparatus was made to recognize the specific electronic footprints produced by a VOC mixture interacting with a set of sensors. The change in physicochemical properties of the sensors induced by interaction with VOCs is transduced in a characteristic electrical signal, which allows description of the compounds without having to isolate the different components of the mixture $[43,44]$. The instrument used in this study has been previously used for recognition of very diverse volatile emission sources such as gasoline, coffee, tobacco and even explosives [45-49]. Certainly, our laboratory studies on volatile emission by microorganisms were carried out under optimal growth conditions which may differ from natural environments [50]. Moreover, the volatile mixture produced by a mixed colony of microorganisms is very likely to differ from what a pure culture may release [2].

A comparison of substances found in our samples (and an examination of where else it has been found previously) allowed us to screen substances (that are listed in Table 1), and to point out those which were specific to particular organisms. A major goal was to elucidate compounds that were 
revealed, and afterwards describe where they have been previously found and what significance they might have.

\subsection{Accurateness of Analyses Performed by E-Nose}

PCA revealed a clear distinction between the four fungal species detected by e-nose measurements, i.e., $P$. ramorum, F. poae, T. asperellum and $R$. solani compared to the controls. In strawberry for instance, a strong separation of pathogenic fungi i.e., Botrytis sp., Penicillium sp. and Rhizopus sp. was also based on the first two components of a PCA plot (accounting for $99.4 \%$ of variance) [51]. PCA of sensorial measurements under laboratory conditions also highlighted a strict relationship between the disease severity (potato brown rot) and the responses of the e-nose sensors [52].

A SPME-GC/MS revealed that sensors 1 and 2 were receptive to ethanol (for which GC/MS analysis detected it in F. culmorum, P. cinnamomi and P. ramorum with high confidence). Sensors 3, 4, 11 and 12 were receptive to VOCs in general (sesquiterpenes were frequently observed as well as other VOCs during GC/MS), and this may explain the high average corresponding signals observed. In contrast, the other sensors 5, 6, 9 and 10 may have been reacting to aliphatic hydrocarbons, as their sensitivity range included liquefied petroleum gases such as propane, butane, etc. On the other hand, sensors number 7, 8, 9 and 10 were sensitive to methane ( 7 and 8) or to methane and LP gases (9 and 10) and provided overall weak signals, which may have led to the conclusion that methane did not belong to the main compounds emitted by the tested samples. Furthermore, methane was not found in any sample during SPME-GC/MS.

\subsection{Volatiles Identifying Fungal and Oomycete Species}

\subsubsection{Control Treatments}

Empty Flask Control

SPME-GC/MS analysis yielded a low abundance for the empty flask control chromatogram (order of magnitude $10^{7}$ ), compared to some other treatments. However, the empty flask control atmosphere contained some volatiles, which was consistent with the e-nose sensing a very weak, but still detectable, signal for this control treatment (Figure 1a). 2-ethyl-1-hexanol, tetradecane, and butylated hydroxytoluene are all compounds that may be found in adhesives, glues, gums, mastics, waxes, etc. For instance, 2-ethyl-1-hexanol is among the most highly produced worldwide synthetic alcohols and often serves as a solvent, while its ester derivatives have many industrial usages: adhesives, coatings, defoamers, emollients, inks, lubricants, plasticizers, etc. [53,54]. Paraffin wax and similar substances are frequently used as lubricants, insulators, water repellents or coating agents by industry. These include long-chain aliphatic alkanes whose oxidation by sample air could explain the presence of found aliphatic aldehydes (heptanal, octanal, nonanal, decanal and dodecanal). All these compounds were probably emitted by the silicone ring adjoined to the inner side of the lid by the manufacturer to allow hermetic closure of the flask, which thus appeared not to be chemically inert. Exposure to high temperatures during sterilization may have caused or facilitated volatile emission.

\section{PDA Medium Control}

The order of magnitude of the PDA control chromatogram was equivalent to what was obtained for the empty flask control $\left(10^{7}\right)$, even though the e-nose analysis showed the former to release higher levels of detectable odors than the latter. Nonanal, decanal, dodecanal and butylated hydroxytoluene were found here again, suggesting these compounds may be released by the flask and not the nutritive medium itself. Furthermore, several of the molecules detected in PDA control that were not detected from the empty flask (benzaldehyde, dodecane, etc.) may also have arisen from the glue, rubber and other synthetic materials [55], making it uncertain the exact origin of these observed volatiles. 


\subsubsection{Armillaria Species}

In accordance with e-nose analysis results, SPME-GC/MS indicated a similar chromatogram signal intensity between controls and Armillaria treatments $\left(10^{7}\right)$. Detected sesquiterpenes in Armillaria treatment (1,3,4,5,6,7-hexahydro-2,5,5,-trimethyl-2H-2,4a-ethanonaphthalene, $\beta$-barbatene, (Z)- $\alpha$-bisabolene and $\delta$-cadinene) were likely to have been emitted by the fungi themselves. Possible presence of 1,3,4,5,6,7-hexahydro-2,5,5-trimethyl-2H-2,4a-ethanonaphthalene and 4,4-dimethylpent-2-enal, common to both A. gallica and A. ostoyae, suggest intrageneric similarities in VOC emission for the Armillaria genus. Furthermore, the detection of $\beta$-barbatene in both A. ostoyae (a basidiomycete) and F. poae (an ascomycete) suggested possible similarities in VOC emission ranges of two different fungal divisions. $\beta$-barbatene is known to have been highlighted among volatiles of several Ascomycota (Fusarium verticillioides) and Basidiomycota (Fomitopsis pinicola, Piptoporus betulinus and Trametes suaveolens) [56]. In addition to the widespread 1-octen-3-ol and its C8 derivatives (such as 2-octen-1-al), fungi frequently emit mixtures of non-ramified, saturated or unsaturated, alcohols, aldehydes, esters and ketones, as well as various ramified methylated molecules [57]. Even though fungi are known to produce large amounts of terpenes, these molecules are found in some bacteria as well, particularly actinomycetes $[58,59]$. Some of these compounds directly act on the emitting organism's close environment whereas others serve as intermediates in mycotoxins or other bioactive molecules biosynthetic pathways [60].

Detection of root rot by Armillaria species is currently very important in the green areas in contemporary cities. Harsh urban conditions such as soil compaction cause tree weakness and mortality of roots being covered by asphalt or bricks limiting access to oxygen and water. Most electronic devices such as resistographs or sound tomographs (PICUS) are designed for checking rot in tree trunks. There is no device for root examination without causing significant damage to plant tissues. In such circumstances the e-nose could address the issue of evaluating hazardous old trees and for the risk of dropping limbs or falling over, especially along streets where they might be poorly anchored.

\subsubsection{Fusarium Species}

The genus Fusarium is one of the most dangerous to germinating seeds, causing damping-off seedlings. There is also a significant menace of introducing the quarantine pathogen F. circinatum from southern Europe, so early warnings about their unintentional entrance and establishment are needed.

\section{Fusarium avenaceum}

The higher observed abundance magnitude $\left(10^{8}\right)$ in the F. poae chromatogram compared to the other studied Fusarium species (usually at $10^{7}$ ) was consistent with e-nose results indicating that this species was linked to a stronger sensor signal. The fact that longifolene was detected in F. avenaceum as well as in $F$. poae points towards possible intrageneric commonality in sesquiterpene emission. Furan and its derivatives (i.e., 2,4-dimethylfuran, but also 2-methylfuran, 3-methylfuran, 2,5-dimethylfuran, 2,3,5-trimethylfuran, 2-ethyl-5-methylfuran, etc.) are found in volatiles emitted by many fungal species. Moreover, the compound 1-octen-3-ol and its C8 co-metabolites can often be found together with 2-pentylfuran, which suggests a common biosynthetic pathway for these molecules. Other furan-derived compounds such as for instance 2-acetylfuran, 2-furanmethanol, 2-(methoxymethyl)furan and furfural are frequent as well [61]. $\beta$-bazzanene is, like trichodiene, an important precursor of various sesquiterpenoids in fungal metabolism [62]. Trichothecene mycotoxins for instance include powerful inhibiting compounds of eukaryotic protein biosynthesis [63].

\section{Fusarium culmorum}

Production of ethyl acetate is common in yeasts, but has been observed in filamentous fungi such as Ceratocystis fagacearum [64]. The F. culmorum flask atmosphere appeared to contain several sesquiterpenes, as did all fungi (except $R$. solani) that were investigated in this study. These molecules 
most likely did come from the fungi and were not emitted by inert bodies of the sample (flask or medium).

\section{Fusarium oxysporum}

Benzaldehyde, which was found in F. oxysporum and in the PDA control, may have been produced by the medium rather than the fungus itself. However, this molecule could theoretically have been emitted by the fungus, since benzene alkylated derivatives have been found to be produced by several fungal genera such as Fusarium, Muscodor, Penicillium and Trichoderma [57]. Whether these compounds fulfill any biological role or are just metabolic waste products still needs clarification. Benzaldehyde itself counts as one of the most widespread benzene derivatives among fungi (especially in the genera Aspergillus, Botrytis, Fomes, Fusarium, Penicillium and Pleurotus). Benzyl alcohol, methyl benzoate, ethyl benzoate and 4-methylbenzaldehyde are less common. Emission of benzothiazole was witnessed in Aspergillus and Trichoderma genera, even though pyrazines remain the most important group of nitrogenous fungal VOCs. Historically, the first aromatic fungal VOCs were identified in the middle of the 20th century in odoriferous decomposing wood. These molecules were thought to be synthetized from tyrosine and phenylalanine aromatic amino-acids or simply result from lignin degradation. The detected 3-chloro-4-methoxybenzaldehyde could have theoretically been released by the fungus as well, even though paraffine-derived chloroalkanes often serve in industry as ingredients for dyes and paste manufacturing. Indeed, chlorine aromatic compounds such as 4-chloro-1,2-dimethoxybenzene and 1,5-dichloro-2,3-dimethoxybenzene have been detected in the genus Geniculosporium [65]. Moreover, 3-chloro-4-methoxybenzaldehyde and 1,5-dichloro-2,3-dimethoxybenzene were identified in Anthracophyllum discolor, along with 3,5-dichloro-4-methoxybenzaldehyde [66]. The latter two molecules were furthermore observed in Bjerkandera adusta, together with their alcohol derivatives. Such compounds can be synthetized by fungi from the growth medium even if its chlorine concentration is very low. Analogous brominated compounds may be produced the same way, whereas iodine specks in growth medium can lead to diiodomethane or even chloroiodomethane biosynthesis according to Spinnler et al. [67].

\section{Fusarium poae}

We found Matsutake alcohol, chemically called 1-octen-3-ol, which is a fatty acid characteristic for fungi widespread in the form of its R-enantiomer [68,69]. The R-enantiomer releases a fruity odor reminiscent of mushrooms, whereas the L-enantiomer is associated with grassy smell [70]. Initially detected in other fungi which were not tested in our experiment, such as Tricholoma matsutake, the alcohol has since then been identified in a wide range of fungal genera such as Agaricus, Aspergillus, Boletus, Fistulina, Fomes, Phomopsis, Lentinus, Penicillium, Pleurotus, Tuber and Verticillium but also in cultivated Fusarium and Trichoderma [57]. The compound 1-octen-3-ol is often found together with some of its C8 co-metabolites: octan-3-ol, octan-3-one, oct-1-en-3-one, octan-1-ol, oct-2-en-1-ol, octanal, trans-oct-2-enal, oct-1-ene and 1,3-octadiene. Some 1-octen-3-ol, octan-1-ol or octan-3-ol ester derivatives can be present in the mixture as well, in variable amounts. Linoleic acid is considered to serve as primary substrate for matsutake alcohol production, even though the exact biosynthetic pathway remains unclear. Production intensifies when the fruiting body is wounded, which could correspond to a defensive strategy of the fungus [71]. This confirmation of its presence in fungi which can help distinguish them from oomycetes is a significant finding for this study. However, it is worth speculating why 1-octen-3-ol is synthesized. First of all, it probably stops growth of some competing fungi, and indeed it has been found to inhibit conidial germination of several fungal species, including Aspergillus nidulans [72], Lecanicillium fungicola [73] and Penicillium paneum [74]. On the other hand, it was able to induce Trichoderma atroviride conidia germination [75]. This suggests 1-octen-3-ol acts as a hormone influencing fungal development. Its exact role however remains to be clarified. In our experiment we did use a mixture of organisms, but this should be done in future tests since there are reports that interactions between fungi are very important. Very often the volatile compounds are 
produced to inhibit or stimulate growth. Diverse species belonging to Ascomycota and Basidiomycota phyla, such as Trichoderma harzianum, were shown to produce bisabolene [76,77]. We found it from tested Armillaria species. Similarly, several longiborneol sesquiterpene derivatives showing antifungal properties were observed in Fusarium spp. (for instance in F. culmorum and F. graminearum) [78,79]. It was also observed in our study.

\subsubsection{Phytophthora Species}

These organisms are considered to be serious primary pathogens of plants (including many forest tree species) and have often been unintentionally introduced to Europe from Asia. The observed increase of international trade of potted plants (e.g., bonsai) and seeds poses a new risk of establishment of alien, invasive species in forest stands. Also tourism, globalization, and quicker vessels with larger cargos accelerate this phenomenon. Therefore, an early detection of this group of organisms is of special importance.

\section{Phytophthora cactorum}

Acetone is produced by Clostridium acetobutylicum and is frequently used as solvent by industry and research. Another compound-dimethyl disulphide-identified in our study is one of the most common sulfur molecules produced by bacteria, together with dimethyl sulphide, dimethyl trisulphide and S-methyl methanethiosulfonate [58]. Generally, bacteria are known to be more abundant emitters of sulfur compounds than fungi, although these latter may produce such substances as well. Less frequent in fungi, these latter compounds have been observed in several Fusarium and Penicillium species [57], but in our case were found in P. cactorum and T. asperellum. Dimethyl disulphide and other compounds such as benzonitrile, trimethyl disulphide or S-methyl thioacetate are volatiles with important antifungal effects [2]. On the other hand, Aspergillus and Trichoderma genera were shown to emit benzothiazole, which contains both sulfur and nitrogen. Moreover, cheese Penicillium strains can produce sulfur dioxide [80]. According to our results, oomycetes seem to be able to release sulfur compounds as well. Emission of 1-hexanol was witnessed in several fungal species such as Aspergillus flavus or Fusarium fujikuroi, which probably synthesize it as well as other related compounds through fatty acid degradation $[81,82]$.

\section{Phytophthora cinnamomi}

P. cinnamomi was rather poor in terms of VOC diversity. 4-ethyl-2-methoxyphenol is commonly found in beer and wine due to fermentation processes by yeasts from the genus Brettanomyces [83,84], which are fungi rather than oomycetes. 2-ethyl-1-hexanol was previously found in the PDA control, which makes it difficult to guess whether this compound was really emitted by the sample itself or originated from inert sample components. Some of the detected VOCs seemed to be common to P. cinnamomi and other species, including fungi.

\section{Phytophthora plurivora}

Acetoin is an important metabolite (mainly carbon storage, physiological acidification avoidance and NAD/NADH ratio regulation), widespread in nature, emitted by many micro-organisms as soon as these have access to a degradable carbon source [85]. Bach et al. [86] have shown production of 4-hydroxybutanoic acid by Saccharomyces cerevisiae. In our experiment, substances such as acetoin and 4-hydroxybutanoic acid, $\alpha$-Pinene, and $\Delta$-3-Carene were found only in P. plurivora samples.

\section{Phytophthora ramorum}

The peak abundances were higher in the P. ramorum chromatogram than for other Phytophthora species, in agreement with e-nose analysis results. 3-methyl-butanol and similar alcohols are often emitted by endophytic fungi belonging to Phoma and Phomopsis genera, which are able to 
break down cellulose $[87,88]$. More generally, 3-methyl-butanol is frequently observed in fungi, and is probably synthesized from leucine. Ceratocystis paradoxa was the first fungal strain to be witnessed producing 3-methyl-butanol in its volatile mixture [89]. 2-phenylethanol, widespread among microorganisms, is an intermediate of L-phenylalanine aromatic amino acid metabolism. Thus, numerous yeast species (including Candida albicans and Saccharomyces cerevisiae) synthesize it as an antibiotic [90,91]. Rapior et al. [92] observed the presence of 2-phenylethanol in VOC mixtures emitted by several Basidiomycetes species. It is common in many fungi genera: Aspergillus, Chaetomium, Fusarium, Hypoxylon, Lasiodiploida, Penicillium, Polyporus, Trichoderma, Tuber, etc. [57]. Production of 2-phenyethanol using microorganisms could serve the industry to avoid artificial synthesis with implied purification steps, which makes the whole process very expensive [93,94]. P. ramorum in Europe causes sudden larch decline in western Great Britain, so its further spread in Europe should be closely monitored.

\subsubsection{Rhizoctonia solani}

There appeared to be a big difference between the low abundance and diversity of the $R$. solani chromatogram and the strong induced reaction from e-nose sensors (Figure $1 \mathrm{~m}$ ). One possible hypothesis is that this species may emit many volatile inorganic compounds (VICs) detected by the e-nose sensors but not extracted by the SPME fiber. Alternatively, molecules released by R. solani may simply have intrinsically higher stimulation of the e-nose, meaning they "smell" stronger to the sensors. Drilling and Dettner [95] witnessed emission of 3-octanol by Trametes versicolor, independent of 1-octen-3-ol emission.

\subsubsection{Trichoderma asperellum}

Consistent with e-nose results (Figure 1), the T. asperellum chromatogram showed a high abundance magnitude (almost $10^{8}$ ). Literature indicates that trans-dauca-4(11),8-diene was spotted in Omphalotus olearius, along with $\alpha$-barbatene, $\beta$-barbatene and $\gamma$-cadinene [96]. It was also observed in Schizophyllum commune [97] and in Bjerkandera adusta [98]. Isodaucene was detected in several fungal species, such as Tricholomopsis rutilans [99] and Aspergillus fischeri [100]. Cedrene has been isolated in several fungi such as Corynespora cassiicola and Beauveria sulfurescens, but also in soil bacteria Rhodococcus rhodochrous [101]. VOCs emitted by the Trichoderma genus have been shown to play the role of signal compounds for communication between colonies as well as for growth regulation. For instance, molecules such as 3-octanol, 3-octanone and 1-octen-3-ol emitted by conidia of Trichoderma cultures induced conidiation of other colonies from the same genus [75].

\subsubsection{Strategies for Improved Detection}

The compounds mentioned above were often shared among organisms but some of them appeared only once suggesting specificity. However, our list of organisms was very limited so if we were to confirm specificity of some compounds, we would need to do so in the future broader screening of organisms. We could apply precise methods such as GC/MS is to identify chemical compounds or to use e-nose sensors. Both approaches have their advantages and disadvantages. Semiconductor sensors used in the e-noses usually show a wide sensitivity range and a non-linear response with respect to gas concentration. Such sensors provide a quick response, involve a simple (thus inexpensive) circuit design and have a long lifetime. The output signal of a given sensor arises from the superposition of individual effects of every component of the gaseous mixture. Because individual sensors (e.g., TGS-Figaro Gas Sensors) show a lack of selectivity, combining several of them with different cross sensitivities allowed improved performance. On the other hand, too many sensors taken together will increase measurement noise.

In order to know which sensor is suitable for a particular chemical compound or their group, other techniques should be applied e.g., multidimensional data analysis tries to highlight odor patterns that can be used to characterize gaseous mixtures based on identification, comparison and 
classification principles. First studies investigating microbial volatiles involved steam distillation and liquid-liquid extraction followed by compounds concentration and identification [7]. Since the gas chromatography (GC) is becoming an affordable and reliable detection method, scientists have merged the separation, identification and quantification steps into one single analytic process, GC/MS. We also used this technique in our experiments because of its high sensitivity and strong discriminatory ability. GC/MS is today the most used analytical tool for fungal VOC identification [102-104] and is easily coupled to solid-phase microextraction (SPME) techniques for the VOC extraction and concentration, which allows easy progression to environmental sampling and subsequent laboratory analysis [100]. However, it should be noted that results observed depend on both the nature of the fiber used and the extraction method [105]. Artifacts can sometimes appear due to solid sorbents serving for headspace analysis [7]. The atmospheric water content of the sample can also bias GC/MS data since fungal VOC formation is easier in humid ambient air. Furthermore, such physical analyses require some time to be implemented [106], even though GC/MS remains a relatively quick way of analyzing VOC mixtures, which can be furthermore automated for real time profiling of compounds emitted from living fungi [107-109].

Alternatively, other analytical methods may be used for VOC characterization. For example, the simultaneous distillation extraction (SDE) method relies on simultaneously occurring vapor distillation and solvent extraction [105]. It is especially applied for the extraction of high boiling volatiles with the flaw of potentially making false features appear because of the longstanding effect of heat. The selected-ion flow-tube mass spectrometry (SIFT-MS) is a technique allowing for a real time measurements of VOC concentration in a sample's atmosphere, with a high degree of sensitivity (up to a few $\mathrm{ppb}$ ) [110]. It allows quick characterization of a gaseous mixture composed of a wide range of molecules. The proton-transfer-reaction mass spectrometry (PTR-MS) involves the VOC ionization using $\mathrm{H}_{3} \mathrm{O}^{+}$primary ions, which results in the $\mathrm{MH}^{+}$ions production (where $\mathrm{M}$ stands for a neutral organic molecule). These are in turn detected by the means of a quadrupole mass spectrometer [111]. This method provides a sensitivity which is comparable to GC/MS, however in contrast to GC/MS affords the robust analysis of a sample without any pre-processing or pre-concentration $[112,113]$.

Based on what was found in our samples and the above literature review, we hypothesize that some substances (listed in Table 1) are also specific to particular organisms. Even if we do not know their putative functions, we believe that they can be used to discriminate between individual fungal and oomycetes species or at least between genera. The only problem could be obtaining sensors for reasonable prices for the most specific compounds for each organism in order to construct new models of e-nose.

Alternatively, further developments may go in the other direction of determining not just single or a few specific compounds, but to train neural networks (artificial intelligence) how to recognize differences among samples e.g., like pictures. In such a case we are not concerned about the chemistry of VOCs (its content), but the focus is to point out differences between organisms. For this purpose, much empirical data will be needed, as well as technical details that need to be worked out such as timing of each measurement, its temperature, and the required humidity. Furthermore, specific cultural conditions for microbial growth, may also affect the quality and quantity of emitted VOCs.

\section{Materials and Methods}

\subsection{Sample Material Preparation}

In total, 144 jars were tested by e-nose containing pure cultures of strains (one to four-week-old fungi and oomycetes prepared in three repetitions). They consisted of 12 different species important in forestry, and were obtained from stocks kept in the laboratory of the Forest Research Institute (IBL) (Table 2). In addition, three copies of aforementioned organisms were grown for VOC analysis by the GC-SM method. 
Table 2. General characteristics of the fungal and oomycete species tested in the experiment.

\begin{tabular}{ccc}
\hline Treatment & Species & Reference from GenBank \\
\hline Control & - & - \\
1 & Armillaria gallica (Marxm. \& Romagn.) 1987 \\
2 & Armillaria ostoyae (Romagn.) Herink 1973 & DQ115578 ${ }^{1}$ \\
3 & Fusarium avenaceum (Fr.) Sacc. 1886 & DQ115574 \\
4 & Fusarium culmorum (Wm.G. Sm.) Sacc. 1892 & MK560761 \\
5 & Fusarium oxysporum (Schltdl.) 1824 & KP008988 \\
6 & Fusarium poae (Peck) Wollenw. 1913 & MF162321 \\
7 & Phytophthora cactorum (Lebert \& Cohn) J. Schröt. 1886 & MF162318 \\
8 & Phytophthora cinnamomi Rands 1922 & KX242303 \\
9 & Phytophthora plurivora T. Jung \& T.I. Burgess 2009 & KF682434 \\
10 & Phytophthora ramorum Werres, De Cock \& Man in ‘t Veld 2001 & JX276032 \\
11 & Rhizoctonia solani J.G. Kühn 1858 & JF771575 \\
12 & Trichoderma asperellum Samuels, Lieckf. \& Nirenberg 1999 & KU901561 \\
& 1 number available from www.ncbi.nlm.nih.gov. & MT197117
\end{tabular}

Transfers of mycelia were made from stored pure colonies onto PDA (20 g glucose $+15 \mathrm{~g}$ agar $+4 \mathrm{~g}$ potato extract dissolved in $1 \mathrm{~L}$ distilled water) using powder purchased at BTL Ltd. (Łódź, Poland), and cultured at room temperature. The investigated microorganisms were raised in specially constructed $300 \mathrm{~mL}$ glass flasks or $40 \mathrm{~mL}$ glass vials. Each flask was fitted with a 66-mm-diameter lid made of galvanized steel with a silicone ring on the underside to prevent air exchange. Each lid was made a 9-mm-diameter hole covered with sterilization tape to allow subsequent collection of gaseous samples by introducing the e-nose inlet or a SPME syringe inside the flask through the hole, thus removing or piercing the closing tape. Similarly, all vials were sealed by a polypropylene cork provided with a polyisobutylene-polytetrafluoroethylene (PIB-PTFE) septum contiguous to its bottom side. As previously, the cork was perforated so that a SPME syringe could later on be introduced in the vial atmosphere by only piercing the underlying septum. All the dishes were distributed in the prepared PDA medium, sealed and autoclaved at $117^{\circ} \mathrm{C}$ and $0.08 \mathrm{MPa}$ for $20 \mathrm{~min}$, prior to microorganisms' inoculation under sterile conditions. Subsequently, in every week (up to four weeks), each of the three jars for every organism was measured with the e-nose devices.

\subsection{E-nose Device and Measurements}

The e-nose was developed by the Warsaw University of Technology (WUT) based on the e-nose sensing device, which has been used in previous research $[48,49]$ and was made of two homologous sets of gas sensors produced by Figaro Engineering Inc. (Osaka, Japan), which include a semiconductor tin oxide layer and arrays made of six different heated metal oxide gas sensors types (Figaro Engineering Inc. Osaka, Japan). Four sensor types were duplicated inside each array (Table S1). Duplicated sensors of the same array had a slightly different loading setting, so that they don't show exactly the same sensitivity spectrum: their output signals were therefore somewhat different, and for instance the 26xx sensor series family was chosen for its small size and high stability of operation. The sensors were not wired in series but were connected to different analog inputs of the data acquisition unit, one by one, and their loading was tuned in a clean air environment using a potentiometer. Moreover, two sensors measuring, respectively, relative humidity (HIH-3610-002 from Honeywell, Morristowne, NJ, USA), and temperature (LM35DH from Texas Instruments, Dallas, TX, USA) were included in both arrays, since those parameters impact sensor sensitivity (Table S1).

Each of the two independent sensor arrays were seated on a custom designed printed circuit board, and installed in a specially designed optimized test chamber consisting of an aluminum black cylinder (approximately $500 \mathrm{~cm}^{3}$ volume) with both extremities connected to a socket outlet consisting of an $8.5 \mathrm{~mm}$ external diameter rubber tube (Figure 3a,b). Both cylindrical channels were standing nearby, in the same ambient environment. The sensor electrical conductivity (resistance) changed according to the concentration of molecules belonging to their respective sensitivity spectra in the test 
chamber and was converted by a simple electrical circuit into an output tension voltage signal. One set formed the measuring device and was put in contact with the sample atmosphere to be analyzed, whereas the other kept sampling ambient air thus providing a reference signal (Figure 3c). Both sets of sensors delivered their own real time signal when the measurement was launched. However, only the difference was continuously saved and transferred to the computer through a serial communication interface consisting of two 8-Channel Analog Input Modules Rev. D1 type ADAM-4017 built by Advantech (Taipei, Taiwan).

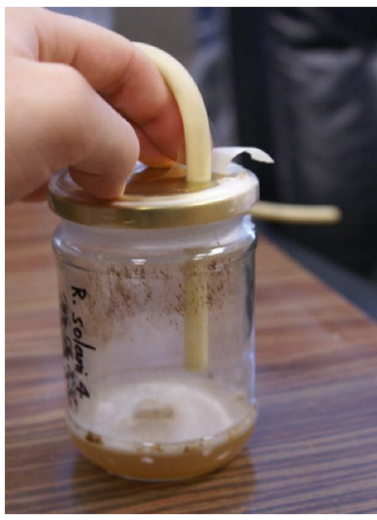

(a)

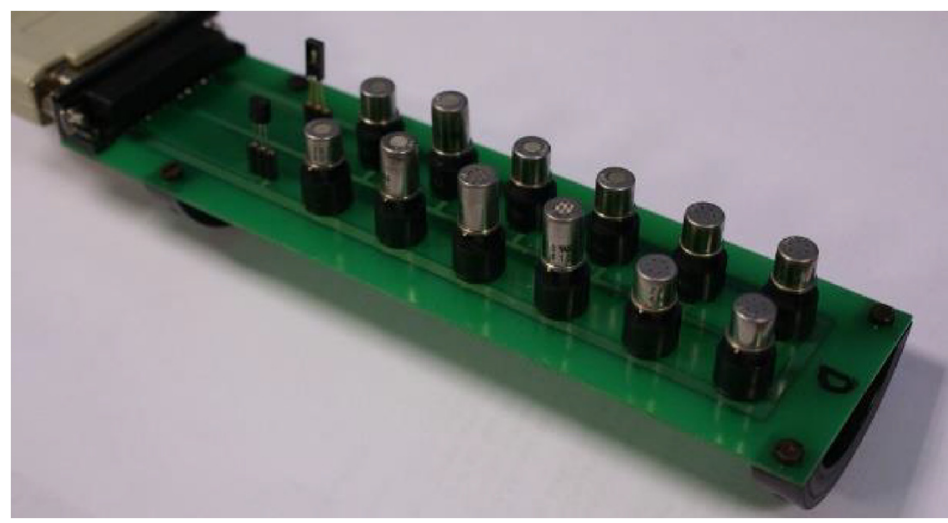

(b)

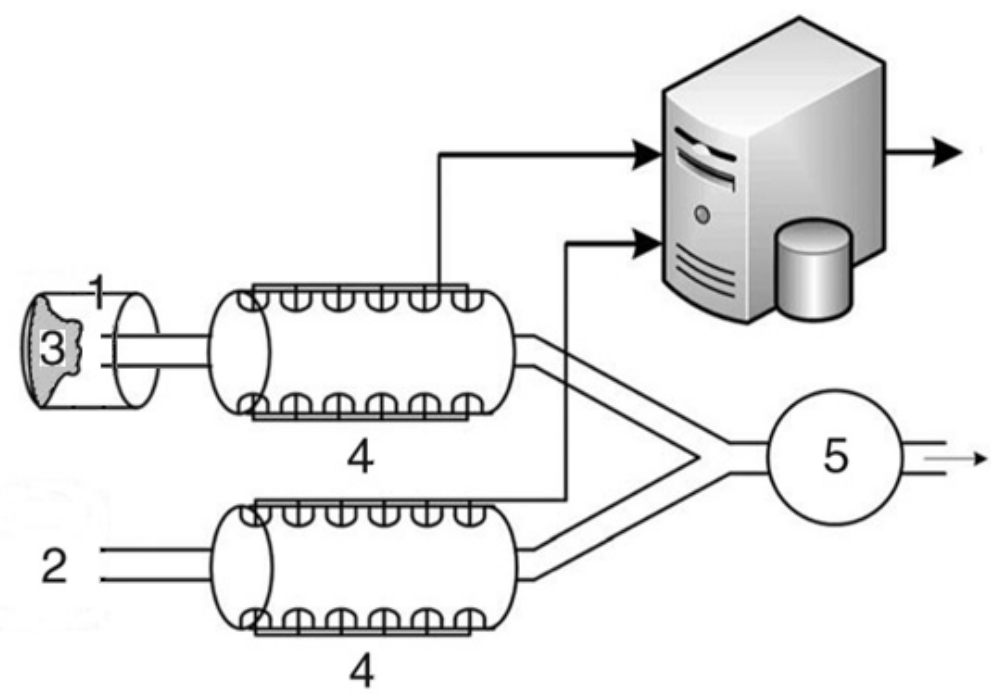

(c)

Figure 3. Representative view of the differential electronic nose apparatus. (a) Introduction of the air intake tube inside the sample; (b) Twelve chemical sensors in an array chamber; (c) General scheme of the e-nose principle of measurement: (1) Sample flask; (2) Ambient air; (3) Tested material; (4) Sensor chambers; (5) Inducting pump and flow-meter. Adapted from Brudzewski et al. [22], Osowski et al. [114].

The deduction between analog signals from both sensor arrays was done by a differential amplifier, whereupon an A/D converter turned the signal into digital format. Differential profiles obtained this way were made of the weighted sum of sensor reaction to the gaseous mixture respective components. This differential functioning removed the need to perform a systematic calibration of the reference signal prior to each measurement at changing conditions of ambient air. It also greatly reduced the influence of natural drift due to ageing of the metal oxide sensors as well as the common distortion 
effect linked with variations of pressure or temperature in the test chamber. Furthermore, the impact of potential intrinsic differences between two homologous sensors or operation errors was in this way minimized. Finally, it increased the sensitivity towards low concentration compounds.

An inducting pump was used to set up the air intake with a laminar and almost one-dimensional flow entering the channel through the socket outlet. It was kept constant by a flowmeter set to $1 \mathrm{~L} \cdot \mathrm{min}^{-1}$. Twelve samples of each treatment were tested by introducing the rubber tube inlet in the sample's atmosphere through the hole on the flask's lid, from which the sterilization tape had been previously removed. The samples were tested at a rate of three per week, up to four weeks after inoculation. Each sample was analyzed only once. The volumes of the test chamber as well as the volume of the sample atmosphere were kept constant during the measurement process. The measurement window duration was arbitrarily set to $300 \mathrm{sec}$ with a resistance sampling rate of 60 times per min. During measurements, which were performed in a dynamic on-line mode, the sensor temperature would fluctuate in a range of 27 to $35^{\circ} \mathrm{C}$, with an almost constant sensor chamber RH of $14-15 \%$.

A washing interval was implemented between every two successive measurements during which the system was let running on itself for typically $10 \mathrm{~min}$ so that the measuring array could desaturate from the preceding sample's atmosphere molecules. However, implementing a more accurate procedure would have meant injecting synthetic air into both test chambers for $15 \mathrm{~min}$. Furthermore, a blank analysis (without submitting any sample to the sensing device) was carried out every time before each new measurement series. Due to imperfect coordination in the setting of homologous sensors of the two sensing arrays, a very low intensity baseline signal would appear which was in turn removed from the pattern yielded from each subsequent analysis.

The experimental data set for each sample consisted of a matrix including 300 vectors in a twelve-dimensional space. Only measured signal values from the final period of the measuring window were used to obtain diagnostic features, so that the signal could settle down and reach a steady state before being considered. Thus, the initial rapidly increasing stage of the sensor signals derived from the transient effect was not taken into account for descriptive features generation, which was done by averaging the second half (last 150 measurements) of every temporal series of sensor resistances $R(\mathrm{j})$, referring to each $j$-th sensor of the array:

$$
r_{(j)}=R_{(j)}-R_{0(j)}
$$

with $R_{(j)}$ representing the averaged measured resistance of the $j$-th sensor of the array and $R_{0(j)}$ standing for the averaged baseline value of resistance measured during the blank analysis, both calculated for the $j$-th sensor of the array based on the last 150 measurements of the corresponding temporal series. Thus, each analyzed sample would yield a final diagnostic feature consisting of a 12-dimensional vector $(\mathrm{r} 1, \ldots, \mathrm{r} 12)$ quantifying the reaction of e-nose sensors exposed to the tested material. Overall, twelve such vectors were obtained per treatment, corresponding to the 12 repetitions performed. Calculating the mean of these 12 diagnostic features allowed us to obtain a global averaged signal vector for each treatment, which could be pictured as a diagram. This final 12-dimensional vector was considered as representing the mean e-nose sensor reaction to the treatment, thus providing an assessment of the tested material odor intensity [22,110].

\subsection{SPME-GC/MS Analysis}

To validate the previously described method of detection with e-nose, VOCs emitted by tested microorganisms were investigated using headspace SPME-GC/MS in two different laboratories at the BUT and at the Institute of Physical Chemistry of the Polish Academy of Sciences in Warsaw (IPC-PAS). A two way approach was performed in order to better detect the VOCs emitted by tested microorganisms, i.e., the first one based on the $85 \mu \mathrm{M}$ PDMS/Carboxen fiber (in the BUT laboratory), and the second one based on $100 \mu \mathrm{M}$ diameter PDMS fiber in the IPC-PAN laboratory. All SPME-GC/MS measurements were for the first time applied to the fungal species, and hence the detailed explanation. 
In the first approach, the samples were analyzed with a SPME syringe including a $85 \mu \mathrm{M}$ diameter PDMS/Carboxen fiber (Supelco, Bellefonte, PA, USA). The fiber was heated to $250{ }^{\circ} \mathrm{C}$ for $1-2 \mathrm{~h}$ after the purchase to remove any potential contaminant adsorbed on the coating. Similarly, this process was repeated for 5-10 min before testing each new set of samples. The fiber was introduced in the flask through the lid hole and placed in an incubator under $40{ }^{\circ} \mathrm{C}$ where a 30 min extraction took place. The fiber was then introduced for $10 \mathrm{~min}$ in the chromatograph injection device, where a temperature of $250{ }^{\circ} \mathrm{C}$ would allow the compounds to be desorbed. The injection was done in a splitless mode. An Agilent 7890A gas chromatograph including a $30 \mathrm{~m} \times 0.25 \mathrm{~mm} \times 0.25 \mu \mathrm{M} \mathrm{HP}-5 \mathrm{MS}$ semipolar capillary column connected to an Agilent 5975C mass spectrometer (Agilent Technologies, Santa Clara, CA, USA) was used for GC/MS analysis, which lasted 43 min overall. From an initial temperature of $35^{\circ} \mathrm{C}$, the oven was heated at a rate of $5^{\circ} \mathrm{C} \mathrm{min}^{-1}$ up to $250{ }^{\circ} \mathrm{C}$. The electron ionization potential was set at $70 \mathrm{eV}$ and the electron ionization (EI) source worked at the temperature of $230^{\circ} \mathrm{C}$. The temperature of the quadrupole analyzer was $150{ }^{\circ} \mathrm{C}$. Helium circulating through the column at a steady flow of $1 \mathrm{~mL} \cdot \mathrm{min}^{-1}$ served as a carrying gas. The spectrometer was working in a full scan mode over a 29-600 mass range. Recorded EI mass spectra were compared against the NIST Mass Spectral Database and Willey libraries for analyte identification. For some unknowns, the identification was supported by an in-house constructed library comprising the EI mass spectra for available standards. In addition to the MS spectra, also RI and authentic standards were used for identification of the compounds.

The IPC-PAS laboratory pursued analyses of the samples with a SPME syringe equipped with a $100 \mu \mathrm{M}$ diameter PDMS fiber (Supelco, Bellefonte, PA, USA). The fiber was preconditioned before each analysis in a GC/MS injector where it was heated at $250{ }^{\circ} \mathrm{C}$ during $30 \mathrm{~min}$. Then, it was introduced in a vial by piercing a cork's underlying septum to perform the extraction, which took place at room temperature and lasted $60 \mathrm{~min}$. Subsequently, a $3 \mathrm{~min}$ desorption was performed at $250{ }^{\circ} \mathrm{C}$ in a GC injector. The injection was done in a splitless mode. The chromatographic analysis lasted overall $28 \mathrm{~min}$ and was performed in a Thermo Trace 1300 gas chromatograph equipped in a $30 \mathrm{~m} \times 0.25 \mathrm{~mm} \times 0.25 \mu \mathrm{M}$ Rtx-5MS semipolar capillary column coupled with a Thermo ITQ 700 mass spectrometer (Thermo Scientific, Waltham, MN, USA). The initial oven temperature was kept isocratic at $100{ }^{\circ} \mathrm{C}$ for $5 \mathrm{~min}$, and then increased at a rate of $10^{\circ} \mathrm{C} \mathrm{min}{ }^{-1}$ to reach a peak temperature of $280{ }^{\circ} \mathrm{C}$ at which it was kept for $5 \mathrm{~min}$. The MS detector was equipped with a $70 \mathrm{eV}$ electron ionization (EI) source. The temperature of the EI ion source was $250^{\circ} \mathrm{C}$, while the quadrupole ion trap analyzer was $250^{\circ} \mathrm{C}$. The carrying gas was helium circulating through a column at a steady flow of $1 \mathrm{~mL} \cdot \mathrm{min}^{-1}$. The spectrometer was working in a full scan mode for a 50-650 mass range. The EI mass spectra obtained were matched with these from the NIST and Willey Mass Spectral Databases for the molecular elucidation.

In both analyses, a ranking showing a list of candidates with the best matches and corresponding estimated confidence rates was generated by the analyzing software. For GC/MS analyses, we used the following software: MSD ChemStation E.02.02.1431, Agilent Technologies and NIST MS Search 2.0. The default analytical software obtained with each instrument was used for calculations for each spotted compound [22,114].

\subsection{Statistical Analysis}

The variability among signals obtained from twelve sensors of the e-nose device was computed by principal component analysis (PCA) in "R" software [115]. PCA analyses as well as the biplot were created with fviz_pca_biplot functions from the "FactoMineR" 1.41 package [116]. The variables with the strongest impact on the distribution of the microorganisms along the principal components were identified on the basis of Pearson correlation coefficients.

To group microorganisms according to their signal similarity among twelve sensors, a hierarchical clustering using Euclidean distance (root sum-of-squares of differences) as the similarity measure and Ward [117] clustering method with the criterion proposed by Murtagh and Legendre [118] were applied. Four different clustering methods, single and complete linkage, the unweighted pair group 
method with arithmetic mean (UPGMA), and Ward's method were tested according to the clustering structure of the dataset [119]. Ward's method was chosen because it expressed the highest value of the agglomerative coefficient. Hierarchical clustering was performed using the Cluster 2.0.7-1 package [120]. Final grouping of microorganisms according to their locations on the PCA biplot were determined visually in Figure 2.

\section{Conclusions}

For the first time, we demonstrated that the e-nose apparatus was able to distinguish between VOCs emitted by the investigated fungi or oomycetes, but further technical developments are still needed for its practical use in the forestry sector in the field or in practice, i.e., nurseries, plantations, stands, or in quarantine laboratories.

Results of testing with the e-nose prototype showed that certain fungal species, such as F. poae, $R$. solani and T. asperellum, were the most odoriferous among the studied organisms, and gave rise to the strongest signals. In our in vitro study, fusaria (F. avenaceum, F. culmorum and F. oxysporum) and an oomycete ( $P$. ramorum) generated moderately intense signals as detected by the e-nose. Two tested Armillaria species, A. gallica, A. ostoyae, and three oomycetes, P. cactorum, P. cinnamomi and P. plurivora, generated specific odors detected by the e-nose sensors, e.g., $\alpha$-Pinene and $\Delta$-3-Carene for P. plurivora. The Principal Component Analysis plot revealed that our system of e-nose detection could discriminate between the odors emitted by P. ramorum, F. poae, R. solani and T. asperellum, making this device suitable for practical use in laboratory situations, at least for the species tested.

Identification of VOCs detected by e-nose was revealed when using two carbon fibers SPMEs. The tested PDMS/Carboxen fiber was more efficient for fungal detection compared to PDMS fiber. The majority of VOCs detected were specific compounds to the genus or species level, due to a complex mixture of (un)saturated (non-)ramified hydrocarbons and their oxygenated derivatives (aldehydes, alcohols, esters). We also noticed that all tested fungal species released sesquiterpenes in variable amounts, apart from R. solani. All tested Phytophthora strains emitted none of these compounds. Therefore, in the future, development of future stage e-nose apparatus will rely on unique volatile compounds identified and specific to investigated microorganisms.

This research should be of special interest for quarantine organizations (e.g., National Plant Protection Organizations or international ones like EPPO) dealing with alien invasive species such as P. ramorum. Further studies need to be carried out with protocol designs allowing control of intraspecific and temporal variability of VOC mixture profiles dependent on environmental conditions, especially in forest nurseries.

Supplementary Materials: The following are available online. Table S1: Composition of the sensor array used for e-nose sample detection tests. 1-8: Tagoshima gas sensors were purchased from Figaro Engineering Inc. (Osaka, Japan); 9-10: Relative humidity and temperature sensors were manufactured by Honeywell (Morristowne, NJ, USA) and Texas Instruments (Dallas, TX, USA), respectively; Table S2: Pearson's correlation coefficients between variables and the first two major components, and contribution of variables in principal components and variation explained; Figure S1: Hierarchical clustering of the microorganism-induced sensor signals based on Euclidean distance and Ward's minimum variance clustering method. The groups of similarities were clustered. Control 1-Empty flask; Control 2-PDA medium.

Author Contributions: Conceptualization, F.L. and T.O.; methodology, M.S., M.A., R.S.; chemical analyses and critical interpretation, M.S., M.A., R.S.; investigation, K.S., T.G.; statistical computation, J.A.N., M.K.; writing-original draft preparation, J.L.; writing-review and editing, J.A.N., T.O., M.A., T.H., R.S.; supervision, F.L.; project administration, S.S., R.T.; funding acquisition, T.O., R.T. All authors have read and agreed to the published version of the manuscript.

Funding: This paper was developed with a Scholarship Fund of the Forest Research Institute (Poland). This work was financially supported by the National Centre for Research and Development by the grant "PROZEL" agreement BIOSTRATEG 3/347105/9/NCBR/2017.

Acknowledgments: The authors are grateful to Małgorzata Lissy for technical assistance during sample preparation, to Anna Żółciak and Miłosz Tkaczyk for their advice concerning culture monitoring, and to Leszek Adamowicz, Bronisław Pura and Ryszard Siegoczyński for help in work coordination. 
Conflicts of Interest: The authors declare no conflict of interest. The funders had no role in the design of the study; in the collection, analyses, or interpretation of data; in the writing of the manuscript, or in the decision to publish the results.

\section{References}

1. Schulz, S.; Dickschat, J.S. Bacterial volatiles: The smell of small organisms. Nat. Prod. Rep. 2007, $24,814$. [CrossRef]

2. Garbeva, P.; Hordijk, C.; Gerards, S.; De Boer, W. Volatile-mediated interactions between phylogenetically different soil bacteria. Front. Microbiol. 2014, 5. [CrossRef] [PubMed]

3. Pagans, E.; Font, X.; Sanchez, A. Emission of volatile organic compounds from composting of different solid wastes: Abatement by biofiltration. J. Hazard. Mater. 2006, 131, 179-186. [CrossRef] [PubMed]

4. Schmidt, R.; Cordovez, V.; De Boer, W.; Raaijmakers, J.; Garbeva, P. Volatile affairs in microbial interactions. ISME J. 2015, 9, 2329-2335. [CrossRef] [PubMed]

5. Herrmann, A. The Chemistry and Biology of Volatiles; Wiley: Chichester, UK; Hoboken, NJ, USA, 2010; ISBN 978-0-470-77778-7.

6. Korpi, A.; Järnberg, J.; Pasanen, A.-L. Microbial Volatile Organic Compounds. Crit. Rev. Toxicol. 2009, 39, 139-193. [CrossRef] [PubMed]

7. Hung, R.; Lee, S.; Bennett, J.W. The effects of low concentrations of the enantiomers of mushroom alcohol (1-Octen-3-Ol) on Arabidopsis thaliana. Mycology 2014, 5, 73-80. [CrossRef]

8. Zeringue, H.J.; Bhatnagar, D.; Cleveland, T.E. $\mathrm{C}_{(15)} \mathrm{H}(24)$ volatile compounds unique to aflatoxigenic strains of Aspergillus flavus. Appl. Environ. Microbiol. 1993, 59, 2264-2270. [CrossRef]

9. Insam, H.; Seewald, M.S.A. Volatile organic compounds (VOCs) in soils. Biol. Fertil. Soils 2010, 46, $199-213$. [CrossRef]

10. Romoli, R.; Papaleo, M.C.; De Pascale, D.; Tutino, M.L.; Michaud, L.; LoGiudice, A.; Fani, R.; Bartolucci, G. GC-MS volatolomic approach to study the antimicrobial activity of the antarctic bacterium Pseudoalteromonas sp. TB41. Metabolomics 2014, 10, 42-51. [CrossRef]

11. Lemfack, M.C.; Nickel, J.; Dunkel, M.; Preissner, R.; Piechulla, B. mVOC: A database of microbial volatiles. Nucleic Acids Res. 2014, 42, D744-D748. [CrossRef]

12. Peñuelas, J.; Asensio, D.; Tholl, D.; Wenke, K.; Rosenkranz, M.; Piechulla, B.; Schnitzler, J.P. Biogenic volatile emissions from the soil: Biogenic volatile emissions from the soil. Plant Cell Environ. 2014, 37, 1866-1891. [CrossRef] [PubMed]

13. Ortíz-Castro, R.; Contreras-Cornejo, H.A.; Macías-Rodríguez, L.; López-Bucio, J. The role of microbial signals in plant growth and development. Plant Signal. Behav. 2009, 4, 701-712. [CrossRef] [PubMed]

14. Piechulla, B.; Degenhardt, J. The emerging importance of microbial volatile organic compounds: The emerging importance of microbial volatile organic compounds. Plant Cell Environ. 2014, 37, 811-812. [CrossRef] [PubMed]

15. Kramer, R.; Abraham, W.-R. Volatile sesquiterpenes from fungi: What are they good for? Phytochem. Rev. 2012, 11, 15-37. [CrossRef]

16. Peghaire, E.; Hamdache, S.; Galien, A.; Sleiman, M.; Ter Halle, A.; El Alaoui, H.; Kocer, A.; Richard, C.; Goupil, P. Inducing plant defense reactions in tobacco plants with phenolic-rich extracts from red maple leaves: A characterization of main active ingredients. Forests 2020, 11, 705. [CrossRef]

17. Claeson, A.-S.; Sandström, M.; Sunesson, A.-L. Volatile organic compounds (VOCs) emitted from materials collected from buildings affected by microorganisms. J. Environ. Monit. 2007, 9, 240-245. [CrossRef] [PubMed]

18. Dalilla, C.R.; Mauricio, B.F.; Simone, C.B.; Silvia, B.; Sergio, F.P. Antimicrobial activity of volatile organic compounds and their effect on lipid peroxidation and electrolyte loss in Colletotrichum gloeosporioides and Colletotrichum acutatum mycelia. Afr. J. Microbiol. Res. 2015, 9, 1527-1535. [CrossRef]

19. Šimpraga, M.; Ghimire, R.P.; Van Der Straeten, D.; Blande, J.D.; Kasurinen, A.; Sorvari, J.; Holopainen, T.; Adriaenssens, S.; Holopainen, J.K.; Kivimäenpää, M. Unravelling the functions of biogenic volatiles in boreal and temperate forest ecosystems. Eur. J. For. Res. 2019, 138, 763-787. [CrossRef]

20. Wilkens, W.F.; Hartman, J.D. An Electronic Analog for the Olfactory Processes. J. Food Sci. 1964, 29, 372-378. [CrossRef] 
21. Gardner, J.W.; Bartlett, P.N. (Eds.) Sensors and Sensory Systems for An Electronic Nose; Kluwer Academic: Boston, MA, USA; Dordrecht, The Netherlands; New York, NY, USA, 1992. [CrossRef]

22. Brudzewski, K.; Osowski, S.; Ulaczyk, J. Differential electronic nose of two chemo sensor arrays for odor discrimination. Sens. Actuators B Chem. 2010, 145, 24-249. [CrossRef]

23. Persaud, K.; Dodd, G. Analysis of discrimination mechanisms in the mammalian olfactory system using a model nose. Nature 1982, 299, 352-355. [CrossRef] [PubMed]

24. Gardner, J.W. Pattern recognition in the Warwick Electronic Nose. In 8th Int Congress of European Chemoreception Research Organisation; University of Warwick: Warwick, UK, 1987.

25. Di Pietrantonio, F.; Benetti, M.; Cannatà, D.; Verona, E.; Palla-Papavlu, A.; Fernández-Pradas, J.M.; Serra, P.; Staiano, M.; Varriale, A.; D'Auria, S. A surface acoustic wave bio-electronic nose for detection of volatile odorant molecules. Biosens. Bioelectron. 2015, 67, 516-523. [CrossRef] [PubMed]

26. Wilson, A.D. Diverse applications of electronic-nose technologies in agriculture and forestry. Sensors 2013, 13, 2295-2348. [CrossRef] [PubMed]

27. Okorski, A.; Pszczółkowska, A.; Gorzkowska, A.; Okorska, S.; Głuszek, P. Fungi associated with conifer seedlings grown in forest nurseries under different systems. EEMJ 2019, 18, 1509-1517. [CrossRef]

28. Jung, T.; Orlikowski, L.; Henricot, B.; Abad-Campos, P.; Aday, A.G.; Aguín Casal, O.; Bakonyi, J.; Cacciola, S.O.; Cech, T.; Chavarriaga, D.; et al. Widespread Phytophthora infestations in European nurseries put forest, semi-natural and horticultural ecosystems at high risk of Phytophthora diseases. For. Pathol. 2016, 46, 134-163. [CrossRef]

29. Adams, R. Identification of Essential Oil Components by Gas Chromatography/Mass Spectrometry, 4th ed.; Allured Publishing Corporation: Carol Stream, IL, USA, 2017.

30. Miyazawa, M.; Marumoto, S.; Kobayashi, T.; Yoshida, S.; Utsumi, Y. Determination of Characteristic Components in Essential Oils from Wisteria Braphybotrys Using Gas Chromatography-Olfactometry Incremental Dilution Technique, Rec. Nat. Prod. 2011, 5, 221-227.

31. Adams, R.P.; Morris, J.A.; Pandey, R.N.; Schwarzbach, A.E. Cryptic speciation between Juniperus deltoides and Juniperus oxycedrus (Cupressaceae) in the Mediterranean. Biochem. Syst. Ecol. 2005, 33, 771-787. [CrossRef]

32. Elmore, J.S.; Mottram, D.S.; Enser, M.; Wood, J.D. Effect of the polyunsaturated fatty acid composition of beef muscle on the profile of aroma volatiles. J. Agric. Food Chem. 1999, 47, 1619-1625. [CrossRef]

33. Wang, Z.; Fingas, M.; Li, K. Fractionation of a light crude oil and identification and quantitation of aliphatic, aromatic, and biomarker compounds by GC-FID and GC-MS, Part II. J. Chromatogr. Sci. 1994, 32, 367-382. [CrossRef]

34. Kotowska, U.; Zalikowski, M.; Isidorov, V.A. HS-SPME/GC-MS analysis of volatile and semi-volatile organic compounds emitted from municipal sewage sludge. Environ. Monit. Asses. 2012, 184, 2893-2907. [CrossRef]

35. Bonaiti, C.; Irlinger, F.; Spinnler, H.E.; Engel, E. An iterative sensory procedure to select odor-active associations in complex consortia of microorganisms: Application to the construction of a cheese model. J. Dairy Sci. 2005, 88, 1671-1684. [CrossRef]

36. Isidorov, V.A.; Zenkevich, I.G.; Krajewska, U.; Dubis, E.N.; Jaroszynska, J.; Bal, K. Gas chromatographic analysis of essential oils with preliminary partition of components. Phytochem. Anal. 2001, 12, 87-90. [CrossRef] [PubMed]

37. Larsen, T.O.; Frisvad, J.C. Characterization of volatile metabolites from 47 Penicillium taxa. Mycol. Res. 1995, 99, 1153-1166. [CrossRef]

38. Goodner, K.L. Practical retention index models of OV-101, DB-1, DB-5, and DB-Wax for flavor and fragrance compounds. LWT 2008, 41, 951-958. [CrossRef]

39. Steinhaus, P.; Schieberle, P. Characterization of the key aroma compounds in soy sauce using approaches of molecular sensory science. J. Agric. Food Chem. 2007, 55, 6262-6269. [CrossRef] [PubMed]

40. Jordan, M.J.; Margaria, C.A.; Shaw, P.E.; Goodner, K.L. Aroma active components in aqueous Kiwi fruit essence and Kiwi fruit puree by GC-MS and multidimensional GC/GC-O. J. Agric. Food Chem. 2002, 50, 5386-5390. [CrossRef]

41. Liu, Y.; Xu, X.-L.; Zhou, G.-H. Comparative study of volatile compounds in traditional Chinese Nanjing marinated duck by different extraction techniques. Int. J. Food Sci. Technol. 2007, 42, 543-550. [CrossRef] 
42. Jalali-Heravi, M.; Zekavat, B.; Sereshti, H. Characterization of essential oil components of Iranian geranium oil using gas chromatography-mass spectrometry combined with chemometric resolution techniques. J. Chromatogr. A 2006, 1114, 154-163. [CrossRef]

43. Wilson, A.D.; Baietto, M. Applications and advances in electronic-nose technologies. Sensors 2009, 9, 5099-5148. [CrossRef]

44. Wilson, A.D.; Baietto, M. Advances in Electronic-Nose Technologies Developed for Biomedical Applications. Sensors 2011, 11, 1105-1176. [CrossRef]

45. Osowski, S.; Linh, T.H.; Brudzewski, K. Neuro-fuzzy TSK network for calibration of semiconductor sensor array for gas measurements. IEEE Trans. Instrum. Meas. 2004, 53, 630-637. [CrossRef]

46. Brudzewski, K.; Osowski, S.; Markiewicz, T.; Ulaczyk, J. Classification of gasoline with supplement of bio-products by means of an electronic nose and SVM neural network. Sens. Actuators B Chem. 2006, 113, 135-141. [CrossRef]

47. Brudzewski, K.; Osowski, S.; Pawlowski, W. Metal oxide sensor arrays for detection of explosives at sub-parts-per million concentration levels by the differential electronic nose. Sens. Actuators B Chem. 2012, 161, 528-533. [CrossRef]

48. Brudzewski, K.; Osowski, S.; Golembiecka, A. Differential electronic nose and support vector machine for fast recognition of tobacco. Expert Syst. Appl. 2012, 39, 9886-9891. [CrossRef]

49. Brudzewski, K.; Osowski, S.; Dwulit, A. Recognition of coffee using differential electronic nose. IEEE Trans. Instrum. Meas. 2012, 61, 1803-1810. [CrossRef]

50. Weise, T.; Kai, M.; Gummesson, A.; Troeger, A.; Von Reuß, S.; Piepenborn, S.; Kosterka, F.; Sklorz, M.; Zimmermann, R.; Francke, W.; et al. Volatile organic compounds produced by the phytopathogenic bacterium Xanthomonas campestris pv. vesicatoria 85-10. Beilstein J. Org. Chem. 2012, 8, 579-596. [CrossRef]

51. Pan, L.; Zhang, W.; Zhu, N.; Mao, S.; Tu, K. Early detection and classification of pathogenic fungal disease in post-harvest strawberry fruit by electronic nose and gas chromatography-mass spectrometry. Food Res. Int. 2014, 62, 162-168. [CrossRef]

52. Biondi, E.; Blasioli, S.; Galeone, A.; Spinelli, F.; Cellini, A.; Lucchese, C.; Braschi, I. Detection of potato brown rot and ring rot by electronic nose: From laboratory to real scale. Talanta 2014, 129, 422-430. [CrossRef]

53. Rettinger, K.; Burschka, C.; Scheeben, P.; Fuchs, H.; Mosandl, A. Chiral 2-alkylbranched acids, esters and alcohols. Preparation and stereospecific flavour evaluation. Tetrahedron Asymmetry 1991, 2, 965-968. [CrossRef]

54. Bahrmann, H.; Hahn, H.-D.; Mayer, D.; Frey, G.D. 2-Ethylhexanol. In Ullmann's Encyclopedia of Industrial Chemistry; Wiley-VCH Verlag GmbH \& Co. KGaA: Weinheim, Germany, 2013; ISBN 978-3-527-30673-2.

55. Engels, H.W.; Weidenhaupt, H.J.; Abele, M.; Pieroth, M.; Hofmann, W. Rubber, 4. Chemicals and additives. In Ullmann's Encyclopedia of Industrial Chemistry; Wiley-VCH Verlag GmbH \& Co. KGaA: Weinheim, Germany, 2000. [CrossRef]

56. Dickschat, J.S.; Brock, N.L.; Citron, C.A.; Tudzynski, B. Biosynthesis of sesquiterpenes by the fungus Fusarium verticillioides. ChemBioChem 2011, 12, 2088-2095. [CrossRef]

57. Dickschat, J.S. Fungal volatiles-a survey from edible mushrooms to moulds. Nat. Prod. Rep. 2017, 34, 310-328. [CrossRef] [PubMed]

58. Citron, C.A.; Gleitzmann, J.; Laurenzano, G.; Pukall, R.; Dickschat, J.S. Terpenoids are widespread in actinomycetes: A correlation of secondary metabolism and genome data. ChemBioChem 2012, 13, 202-214. [CrossRef] [PubMed]

59. Yamada, Y.; Kuzuyama, T.; Komatsu, M.; Shin-ya, K.; Omura, S.; Cane, D.E.; Ikeda, H. Terpene synthases are widely distributed in bacteria. Proc. Nat. Acad. Sci. USA 2015, 112, 857-862. [CrossRef] [PubMed]

60. Yamagiwa, Y.; Inagaki, Y.; Ichinose, Y.; Toyoda, K.; Hyakumachi, M.; Shiraishi, T. Talaromyces wortmannii FS2 emits $\beta$-caryphyllene, which promotes plant growth and induces resistance. J. Gen. Plant Pathol. 2011, 77, 336-341. [CrossRef]

61. Matsui, K.; Sasahara, S.; Akakabe, Y.; Kajiwara, T. Linoleic acid 10-hydroperoxide as an intermediate during formation of 1-octen-3-ol from linoleic acid in Lentinus decadetes. Biosci. Biotechnol. Biochem. 2003, 67, 2280-2282. [CrossRef]

62. Suda, M. Short-step syntheses of ( \pm )-bazzanene and $( \pm)$ trichodiene. Tetrahedron Lett. 1982, 23, 427-428. [CrossRef] 
63. Zamir, L.O.; Gauthier, M.J.; Devor, K.A.; Nadeau, Y.; Sauriol, F. Trichodiene is a precursor to trichothecenes. J. Chem. Soc. Chem. Commun. 1989, 9, 598-600. [CrossRef]

64. Lin, H.; Phelan, P.L. Comparison of volatiles from beetle-transmitted Ceratocystis fagacearum and four non-insect-dependent fungi. J. Chem. Ecol. 1992, 18, 1623-1632. [CrossRef]

65. Wang, T.; Rabe, P.; Citron, C.A.; Dickschat, J.S. Halogenated volatiles from the fungus Geniculosporium and the actinomycete Streptomyces chartreusis. Beilstein J. Org. Chem. 2013, 9, 2767-2777. [CrossRef]

66. Schalchli, H.; Hormazábal, E.; Becerra, J.; Briceño, G.; Hernández, V.; Rubilar, O.; Diez, M.C. Volatiles from white-rot fungi for controlling plant pathogenic fungi. Chem. Ecol. 2015, 31, 754-763. [CrossRef]

67. Spinnler, H.E.; De Jong, E.; Mauvais, G.; Semon, E.; Le Quéré, J.L. Production of halogenated compounds by Bjerkandera adusta. Appl. Microbiol. Biotechnol. 1994, 42, 212-221. [CrossRef]

68. Zawirska-Wojtasiak, R. Optical purity of (R)-(-)-1-octen-3-ol in the aroma of various species of edible mushrooms. Food Chem. 2004, 86, 113-118. [CrossRef]

69. Thakeow, P.; Angeli, S.; Weißbecker, B.; Schütz, S. Antennal and behavioral responses of Cis boleti to fungal odor of Trametes gibbosa. Chem. Senses 2008, 33, 379-387. [CrossRef] [PubMed]

70. Mosandl, A.; Heusinger, G.; Gessner, M. Analytical and sensory differentiation of 1-octen-3-ol enantiomers. J. Agric. Food Chem. 1986, 34, 119-122. [CrossRef]

71. Spiteller, P. Chemical defence strategies of higher fungi. Chem. A Eur. J. 2008, 14, 9100-9110. [CrossRef]

72. Heddergott, C.; Calvo, A.M.; Latgé, J.P. The volatome of Aspergillus fumigatus. Eukaryot. Cell 2014, 13, 1014-1025. [CrossRef]

73. Berendsen, R.L.; Schrier, N.; Kalkhove, S.I.; Lugones, L.G.; Baars, J.J.; Zijlstra, C.; De Weerdt, M.; Wösten, H.A.B.; Bakker, P.A.H.M. Absence of induced resistance in Agaricus bisporus against Lecanicillium fungicola. Antonie Van Leeuwenhoek 2013, 103, 539-550. [CrossRef]

74. Chitarra, G.S.; Abee, T.; Rombouts, F.M.; Posthumus, M.A.; Dijksterhuis, J. Germination of Penicillium paneum conidia is regulated by 1-octen-3-ol, a volatile self-inhibitor. Appl. Environ. Microbiol. 2004, 70, 2823-2829. [CrossRef]

75. Nemčovič, M.; Jakubíková, L.; Ví-den, I.; Farkaš, V. Induction of conidiation by endogenous volatile compounds in Trichoderma spp. FEMS Microbiol. Lett. 2008, 284, 231-236. [CrossRef]

76. Müller, A.; Faubert, P.; Hagen, M.; Zu Castell, W.; Polle, A.; Schnitzler, J.P.; Rosenkranz, M. Volatile profiles of fungi-chemotyping of species and ecological functions. Fungal Genet. Biol. 2013, 54, 25-33. [CrossRef]

77. Zhang, M.; Zhao, J.L.; Liu, J.M.; Chen, R.D.; Xie, K.B.; Chen, D.W.; Feng, K.P.; Zhang, D.; Dai, J.G. Neural anti-inflammatory sesquiterpenoids from the endophytic fungus Trichoderma sp. Xy24. J. Asian Nat. Prod. Res. 2017, 19, 651-658. [CrossRef] [PubMed]

78. Takasu, K.; Mizutani, S.; Noguchi, M.; Makita, K.; Ihara, M. Total Synthesis of ( \pm )-culmorin and ( \pm )-longiborneol: An efficient construction of tricyclo [6.3. 0.03, 9] undecan-10-one by intramolecular double michael addition. J. Org. Chem. 2000, 65, 4112-4119. [CrossRef] [PubMed]

79. McCormick, S.P.; Alexander, N.J.; Harris, L.J. CLM1 of Fusarium graminearum encodes a longiborneol synthase required for culmorin production. Appl. Environ. Microbiol. 2010, 76, 136-141. [CrossRef] [PubMed]

80. Larsen, T.O. Volatile flavour production by Penicillium caseifulvum. Int. Dairy J. 1998, 8, 883-887. [CrossRef]

81. Brock, N.L.; Tudzynski, B.; Dickschat, J.S. Biosynthesis of sesqui-and diterpenes by the gibberellin producer Fusarium fujikuroi. ChemBioChem 2011, 12, 2667-2676. [CrossRef] [PubMed]

82. Studt, L.; Janevska, S.; Niehaus, E.M.; Burkhardt, I.; Arndt, B.; Sieber, C.M.; Humpf, H.U.; Dickschat, J.S.; Tudzynski, B. Two separate key enzymes and two pathway-specific transcription factors are involved in fusaric acid biosynthesis in Fusarium fujikuroi. Environ. Microbiol. 2016, 18, 936-956. [CrossRef] [PubMed]

83. Pollnitz, A.P.; Pardon, K.H.; Sefton, M.A. Quantitative analysis of 4-ethylphenol and 4-ethylguaiacol in red wine. J. Chromatogr. A 2000, 874, 101-109. [CrossRef]

84. Martorell, N.; Martı, M.P.; Mestres, M.; Busto, O.; Guasch, J. Determination of 4-ethylguaiacol and 4-ethylphenol in red wines using headspace-solid-phase microextraction-gas chromatography. J. Chromatogr. A 2002, 975, 349-354. [CrossRef]

85. Xiao, Z.; Xu, P. Acetoin metabolism in bacteria. Crit. Rev. Microbiol. 2007, 33, 127-140. [CrossRef]

86. Bach, B.; Meudec, E.; Lepoutre, J.P.; Rossignol, T.; Blondin, B.; Dequin, S.; Camarasa, C. New insights into $\gamma$-aminobutyric acid catabolism: Evidence for $\gamma$-hydroxybutyric acid and polyhydroxybutyrate synthesis in Saccharomyces cerevisiae. Appl. Environ. Microbiol. 2009, 75, 4231-4239. [CrossRef] 
87. Singh, S.K.; Strobel, G.A.; Knighton, B.; Geary, B.; Sears, J.; Ezra, D. An endophytic Phomopsis sp. possessing bioactivity and fuel potential with its volatile organic compounds. Microb. Ecol. 2011, 61, 729-739. [CrossRef] [PubMed]

88. Strobel, G.; Singh, S.K.; Riyaz-Ul-Hassan, S.; Mitchell, A.M.; Geary, B.; Sears, J. An endophytic/pathogenic Phoma sp. from creosote bush producing biologically active volatile compounds having fuel potential. FEMS Microbiol. Lett. 2011, 320, 87-94. [CrossRef] [PubMed]

89. Fahlbusch, K.G.; Hammerschmidt, F.J.; Panten, J.; Pickenhagen, W.; Schatkowski, D.; Bauer, K.; Garbe, D.; Surburg, H. Flavors and fragrances. In Ulmann's Encyclopedia of Industrial Chemistry; Wiley-VCH Verlag GmbH \& Co. KGaA: Weinheim, Germany, 2000. [CrossRef]

90. Lingappa, B.T.; Prasad, M.; Lingappa, Y.; Hunt, D.F.; Biemann, K. Phenethyl alcohol and tryptophol: Autoantibiotics produced by the fungus Candida albicans. Science 1969, 163, 192-194. [CrossRef] [PubMed]

91. Eshkol, N.; Sendovski, M.; Bahalul, M.; Katz-Ezov, T.; Kashi, Y.A.; Fishman, A. Production of 2-phenylethanol from by a stress tolerant Saccharomyces cerevisiae strain. J. Appl. Microbiol. 2009, 106, 534-542. [CrossRef]

92. Rapior, S.; Cavalié, S.; Croze, P.; Andary, C.; Pélissier, Y.; Bessière, J.M. Volatile components of ten frozen mushrooms (Basidiomycetes). J. Essent. Oil Res. 1996, 8, 63-66. [CrossRef]

93. Gao, F.; Daugulis, A.J. Bioproduction of the aroma compound 2-phenylethanol in a solid-liquid two-phase partitioning bioreactor system by Kluyveromyces marxianus. Biotechnol. Bioeng. 2009, 104, 332-339. [CrossRef]

94. Hua, D.; Xu, P. Recent advances in biotechnological production of 2-phenylethanol. Biotechnol. Adv. 2011, 29, 654-660. [CrossRef]

95. Drilling, K.; Dettner, K. Electrophysiological responses of four fungivorous coleoptera to volatiles of Trametes versicolor: Implications for host selection. Chemoecology 2009, 19, 109. [CrossRef]

96. Wawrzyn, G.T.; Quin, M.B.; Choudhary, S.; López-Gallego, F.; Schmidt-Dannert, C. Draft genome of Omphalotus olearius provides a predictive framework for sesquiterpenoid natural product biosynthesis in Basidiomycota. Chem. Biol. 2012, 19, 772-783. [CrossRef]

97. Ziegenbein, F.C.; Hanssen, H.P.; König, W.A. Chemical constituents of the essential oils of three wood-rotting fungi. Flavour Fragr. J. 2006, 21, 813-816. [CrossRef]

98. Ziegenbein, F.C.; König, W.A.; Hanssen, H.P. Volatile metabolites from the wood-inhabiting fungi Bjerkandera adusta, Ganoderma applanatum, and Stereum hirsutum. J. Essent. Oil Res. 2010, 22, 116-118. [CrossRef]

99. Costa, R.; De Grazia, S.; Grasso, E.; Trozzi, A. Headspace-solid-phase microextraction-gas chromatography as analytical methodology for the determination of volatiles in wild mushrooms and evaluation of modifications occurring during storage. J. Anal. Methods Chem. 2015, 1-10. [CrossRef] [PubMed]

100. Dickschat, J.S.; Celik, E.; Brock, N.L. Volatiles from three genome sequenced fungi from the genus Aspergillus. Beilstein J. Org. Chem. 2018, 14, 900-910. [CrossRef] [PubMed]

101. Takigawa, H.; Kubota, H.; Sonohara, H.; Okuda, M.; Tanaka, S.; Fujikura, Y.; Ito, S. Novel Allylic Oxidation of $\alpha$-Cedrene to sec-Cedrenol by a Rhodococcus Strain. Appl. Environ. Microbiol. 1993, 59, 1336-1341. [CrossRef] [PubMed]

102. Matysik, S.; Herbarth, O.; Mueller, A. Determination of volatile metabolites originating from mould growth on wall paper and synthetic media. J. Microbiol. Methods 2008, 75, 182-187. [CrossRef] [PubMed]

103. Hamad, Y.K.; Abobakr, Y.; Salem, M.Z.; Ali, H.M.; Al-Sarar, A.S.; Al-Zabib, A.A. Activity of plant extracts/essential oils against three plant pathogenic fungi and mosquito larvae: GC/MS analysis of bioactive compounds. BioResources 2019, 14, 4489-4511. [CrossRef]

104. Szmigielski, R.; Cieslak, M.; Rudziński, K.J.; Maciejewska, B. Identification of volatiles from Pinus silvestris attractive for Monochamus galloprovincialis using a SPME-GC/MS platform. Environ. Sci. Pollut. Res. 2012, 19, 2860-2869. [CrossRef] [PubMed]

105. Jeleń, H.H. Use of solid phase microextraction (SPME) for profiling fungal volatile metabolites. Lett. Appl. Microbiol. 2003, 36, 263-267. [CrossRef]

106. Gardner, J.W.; Pearce, T.C.; Friel, S.; Bartlett, P.N.; Blair, N. A multisensor system for beer flavour monitoring using an array of conducting polymers and predictive classifiers. Sens. Actuators B Chem. 1994, 18, 240-243. [CrossRef]

107. Stoppacher, N.; Kluger, B.; Zeilinger, S.; Krska, R.; Schuhmacher, R. Identification and profiling of volatile metabolites of the biocontrol fungus Trichoderma atroviride by HS-SPME-GC-MS. J. Microbiol. Methods 2010, 81, 187-193. [CrossRef] 
108. Zhang, Z.; Li, G. A review of advances and new developments in the analysis of biological volatile organic compounds. Microchem. J. 2010, 95, 127-139. [CrossRef]

109. Nowakowska, J.A.; Stocki, M.; Stocka, N.; Ślusarski, S.; Tkaczyk, M.; Caetano, J.M.; Tulik, M.; Hsiang, M.; Oszako, T. Interactions between Phytophthora cactorum, Armillaria gallica and Betula pendula Roth. Seedlings Subjected to Defoliation. Forests 2020, 11, 1107. [CrossRef]

110. Senthilmohan, S.T.; McEwan, M.J.; Wilson, P.F.; Milligan, D.B.; Freeman, C.G. Real time analysis of breath volatiles using SIFT-MS in cigarette smoking. Redox Rep. 2001, 6, 185-187. [CrossRef] [PubMed]

111. Lindinger, W.; Hansel, A.; Jordan, A. On-line monitoring of volatile organic compounds at pptv levels by means of proton-transfer-reaction mass spectrometry (PTR-MS) medical applications, food control and environmental research. Int. J. Mass Spectrom. Ion Process. 1998, 173, 191-241. [CrossRef]

112. Ezra, D.; Jasper, J.; Rogers, T.; Knighton, B.; Grimsrud, E.; Strobel, G. Proton transfer reaction-mass spectrometry as a technique to measure volatile emissions of Muscodor albus. Plant Sci. 2004, 166, 1471-1477. [CrossRef]

113. Maenhaut, W.; Chi, X.; Wang, W.; Cafmeyer, J.; Yasmeen, F.; Vermeylen, R.; Szmigielska, K.; Janssens, I.; Claeys, M. Contribution from Selected Organic Species to PM2.5 Aerosol during a Summer Field Campaign at K.-Puszta, Hungary. Atmosphere 2017, 8, 221. [CrossRef]

114. Osowski, S.; Siwek, K.; Grzywacz, T.; Brudzewski, K. Differential electronic nose in on-line dynamic measurements. Metrol. Meas. Syst. 2014, 21, 649-662. [CrossRef]

115. R Core Team. R: A Language and Environment for Statistical Computing; R Foundation for Statistical Computing: Vienna, Austria. Available online: https://www.R-project.org/ (accessed on 17 November 2020).

116. Husson, F.; Josse, J.; Le, S.; Mazet, J. Factominer: Multivariate Exploratory Data Analysis and Data Mining. R Package Version 1.29. 2015. Available online: http://cran.r-project.org/package=FactoMineR (accessed on 17 November 2020).

117. Ward, J.H. Hierarchical grouping to optimize an objective function. J. Am. Stat. Assoc. 1963, 58, $236-244$. [CrossRef]

118. Murtagh, F.; Legendre, P. Ward's hierarchical agglomerative clustering method: Which algorithms implement Ward's criterion? J. Classif. 2014, 31, 274-295. [CrossRef]

119. Kaufman, L.; Rousseeuw, P.J. Finding Groups in Data: An Introduction to Cluster Analysis; John Wiley \& Sons, Inc.: Hoboken, NJ, USA, 2008.

120. Rousseeuw, P.; Struyf, A.; Hubert, M.; Studer, M.; Roudier, P.; Gonzalez, J. Package 'Cluster'. Available online: https://cran.r-project.org/web/packages/cluster/index.html (accessed on 17 November 2020).

Sample Availability: Samples of the compounds are not available from the authors.

Publisher's Note: MDPI stays neutral with regard to jurisdictional claims in published maps and institutional affiliations.

(C) 2020 by the authors. Licensee MDPI, Basel, Switzerland. This article is an open access article distributed under the terms and conditions of the Creative Commons Attribution (CC BY) license (http://creativecommons.org/licenses/by/4.0/). 